\title{
Hysteresis and Soil Site Dependent Input and Hysteretic Energy Spectra for Far-Source Ground Motions
}

\author{
Mebrahtom Gebrekirstos Mezgebo ${ }^{1}$ and Eric M. Lui ${ }^{2}$ \\ ${ }^{1}$ Michael Baker International, Hamilton, NJ 08619, USA \\ ${ }^{2}$ Department of Civil and Environmental Engineering, Syracuse University, Syracuse, NY 13244-1240, USA \\ Correspondence should be addressed to Eric M. Lui; emlui@syr.edu
}

Received 30 June 2016; Revised 14 September 2016; Accepted 26 September 2016

Academic Editor: Lucio Nobile

Copyright (c) 2016 M. G. Mezgebo and E. M. Lui. This is an open access article distributed under the Creative Commons Attribution License, which permits unrestricted use, distribution, and reproduction in any medium, provided the original work is properly cited.

\begin{abstract}
Earthquake input energy spectra for four soil site classes, four hysteresis models, and five ductility levels are developed for far-source ground motion effect. These energy spectra are normalized by a quantity called velocity index (VI). The use of VI allows for the creation of dimensionless spectra and results in smaller coefficients of variation. Hysteretic energy spectra are then developed to address the demand aspect of an energy-based seismic design of structures with $5 \%$ critical damping and ductility that ranges from 2 to 5 . The proposed input and hysteretic energy spectra are then compared with response spectra generated using nonlinear time history analyses of real ground motions and are found to produce reasonably good results over a relatively large period range.
\end{abstract}

\section{Introduction}

Performance-based design is a design philosophy that aims at designing structures to resist seismic forces with acceptable damage. The two most widely used performance-based design procedures are the force-based design and displacement-based design methods. In the force-based design (FBD) method, a design seismic force for a target structure is specified on the basis of an elastic acceleration response spectrum. This seismic design force is called the design base shear. To account for inelasticity (ductility effect), the design force of the target structure obtained from the elastic acceleration response spectrum is divided by a force-reduction factor. The structure is then designed for the reduced force, and the displacement can be checked so that the code-specified serviceability limits are met. The FBD method is not without limitations and drawbacks. Smith and Tso [1] through their study on a large class of reinforced concrete members such as piers, flexural walls, and ductile moment resisting fames claimed that force-based design procedure was inconsistent. They argued the assumption that the stiffness of the lateral force resisting elements was essentially independent of their strength was inconsistent as strength and stiffness are usually related. Moreover, the problems associated with this method, as pointed out by Priestley et al. [2] are as follows. (1) The elastic stiffness is not known at the start of the design process, and very approximate values have to be used. (2) Foundation effects are generally ignored in FBD and are difficult to incorporate in the design process as they affect both the elastic period and displacement ductility demand. (3) Even though the design force is calculated from an allowable displacement ductility factor, it does not properly address the force-displacement relationship of the structure.

The displacement-based design (DBD) method takes displacement as a design parameter as opposed to using base shear as in the case for FBD. As a result, the important task in a displacement-based design approach is to estimate the maximum displacement demand in a structure with reasonable simplicity and accuracy as a function of its local mechanical characteristics, such as member strain and deformation limits. FEMA 440 [3] displacement-based coefficient method is one of the currently available displacement-based seismic design methods. The coefficient method modifies the linear elastic response of an equivalent single degree of freedom (SDOF) system by multiplying it by a series of coefficients to estimate a global displacement, commonly termed as the target displacement. This method uses an idealized force-displacement curve (pushover curve), which 
is a plot (for a given damping coefficient) of base shear versus roof displacement developed for a multiple degree of freedom (MDOF) structure. A corresponding spectral value for an effective period, $T_{e}$, of an equivalent SDOF system is then obtained from an elastic response spectrum corresponding to a design ground motion. The target displacement is then calculated using an empirical formula that involves modifying coefficients and the spectral value for the corresponding effective period. The effective period is obtained from an initial period of the structure and accounts for the loss of stiffness in the transition from elastic to inelastic behavior.

The accuracy of the DBD method is highly dependent on how closely the equivalent SDOF system and its corresponding MDOF system are related through the idealized pushover curve. Several researchers have identified glitches in the use of roof displacement-based pushover curve. HernandezMontes et al. [4] noted that the use of roof displacement in generating the capacity curve could be misleading because the capacity curve so obtained sometimes tends to show the structure as a source of energy rather than an entity for absorbing energy. They suggested that an energy-based pushover analysis be used instead whereby the lateral force is plotted against a displacement which is a function of energy. Manoukas et al. [5] also developed an energy-based pushover procedure for estimating structural performance under strong earthquakes. They showed through numerical examples that their procedure provided better results compared to those produced by other similar methods.

It should be noted that neither the FBD method that uses base shear as a design parameter nor the DBD method that uses displacement as a design parameter can directly consider the cumulative damage effect that result from numerous inelastic cycles of vibration due to deterioration of the structure's hysteretic behavior. Moreover, the effect of earthquakes on structures should be interpreted not just as a force or displacement quantity, but as a product of both, that is, in terms of energy. This is the underlying concept for the energy-based seismic design (EBSD) method. In EBSD, a structure is designed so its energy absorbing capacity exceeds the energy demand from earthquakes. To perform EBSD, one needs to address both the capacity and demand sides of the problem. This paper is focused on the demand aspect of EBSD, while the capacity aspect will be discussed in a separate paper. In what follows, the basic concept of EBSD is reviewed, and input and hysteretic energy spectra equations for four soil site classes, four hysteresis models, and five ductility levels will be developed and proposed for use in EBSD.

\section{Energy-Based Seismic Design (EBSD)}

The equation of motion for a single degree of freedom (SDOF) inelastic system under ground motion excitation is given by

$$
m \ddot{u}+c \dot{u}+f_{s}=-m \ddot{u}_{g},
$$

where $m$ is mass of the system; $c$ is damping coefficient; $f_{s}$ is restoring force; $\ddot{u}_{g}$ is ground acceleration; and $\ddot{u}, \dot{u}$, and $u$ are the relative acceleration, velocity, and displacement of the system with respect to the ground, respectively.
The energy balance equation for this SDOF structure based on relative motion can be written as

$$
\int_{0}^{t} m \ddot{u} \dot{u} d t+\int_{0}^{t} c \dot{u} \dot{u} d t+\int_{0}^{t} f_{s} \dot{u} d t=-\int_{0}^{t} m \ddot{u}_{g} \dot{u} d t .
$$

Equation (2) can be rewritten as

$$
E_{\mathrm{kr}}+E_{d}+E_{a}=\mathrm{IE},
$$

where

$$
\begin{aligned}
& E_{\mathrm{kr}}=\text { relative kinetic energy }=\int_{0}^{t} m \ddot{u} \dot{u} d t=\frac{1}{2} m \dot{u}^{2}, \\
& E_{d}=\text { damping energy }=\int_{0}^{t} c \dot{u}^{2} d t, \\
& E_{a}=\text { absorbed energy }=\int_{0}^{t} f_{s} \dot{u} d t, \\
& \mathrm{IE}=\text { relative input energy }=-\int_{0}^{t} m \ddot{u}_{g} \dot{u} d t .
\end{aligned}
$$

$E_{\mathrm{kr}}$ in (3) vanishes when vibration of the structure ceases. $E_{d}$ is related to the inherent viscous damping of the structure and any supplemental damping devices provided to the structure. $E_{a}$ consists of two different types of energy: elastic strain energy, $E_{s}$, and hysteretic energy, HE. Elastic strain energy does not cause permanent deformation, as it occurs as a result of elastic deformation of the structure, is recoverable, and vanishes when vibration ceases. Hysteretic energy is related to the inelastic deformation of the structure and is the energy that is expended through inelastic hysteretic response. It is obtained by subtracting the strain energy recovered during the unloading process from the strain energy accumulated during the loading process [6]. For a given hysteresis model, hysteretic energy is represented by the area enclosed by the hysteresis loops.

The philosophy of EBSD primarily focuses on ensuring that structures are designed to meet the energy demand of an earthquake. In EBSD, if the energy demand of a structure due to an earthquake can be dissipated through damping or a controlled inelastic deformation mechanism in the structure, the design is said to be satisfactory. Therefore, energy is considered to be the main design parameter in any energy-based seismic design procedure. EBSD is believed to be a rational design approach for seismic design because it takes into account the accumulated earthquake induced damage in the design procedure. However, the viability of EBSD depends on the accuracy in developing inelastic design spectra for SDOF as well as the quality of the equations that relate the input energy to the hysteretic energy. Furthermore, when applying to MDOF structures, a reliable and rational procedure for distributing the hysteretic energy over the height of the structure or among the various energy dissipating mechanisms needs to be developed.

\section{Input and Hysteretic Energies}

3.1. Input Energy. Earthquake input energy is the amount of energy an earthquake imparts to a structure. If relative 
velocity of the structure is used in the computation, the resulting input energy as shown in (7) is called the relative input energy. On the other hand, if the relative velocity $\dot{u}$ in the equation is replaced by the total velocity of the structural system $\dot{u}_{t}$, the resulting input energy is referred to as the absolute or total input energy.

In a study by Bruneau and Wang [7] who used closedform energy expression for a SDOF system subjected to rectangular and harmonic base excitation, a close relationship between relative input energy and relative displacement was reported. As a result, they recommended that a relative input energy formulation be used for assessing earthquake damage on structures. Henceforth, the relative input energy IE is used in the present study to quantify the energy content of an earthquake. In another study, Fabrizio et al. [8] performed correlation study between input and hysteretic energies with roof and maximum interstory displacements using six hysteresis models and 900 recorded ground motions. Two pairs of indices were proposed to quantify the correlation for both single degree and multiple degrees of freedom systems.

Over the years a number of researchers have recommended empirical formulae to estimate earthquake input energy. Housner [9] computed the input energy per unit mass of a SDOF system as proportional to the square of the pseudospectral velocity. Akiyama [10], using Japanese design earthquakes, proposed the input energy per unit mass of an elastic SDOF structure due to a given earthquake as proportional to the square of the natural period of vibration of the structure or the predominant period of ground motion, whichever is smaller. Kuwamura and Galambos [11] extended Akiyama's work and included the effects of severity and duration of the earthquake in their energy expression. Fajfar et al. [12], using 40 accelerograms and examining structures that fall within the constant velocity region of the response spectra, proposed an input energy expression as a function of the duration of strong motion as defined by Trifunac and Brady [13] and the peak ground velocity of the ground motion. Uang and Bertero [14], using five accelerograms and the absolute input energy, concluded that Housner's (1956) expression for input energy reflected the maximum elastic energy stored in the structures but did not include the damping energy. Like Fajfar et al., they proposed an expression for the absolute input energy per unit mass as a function of the duration of strong motion and the peak ground velocity of the ground motion. Manfredi [15], using 244 accelerograms, proposed an input energy expression that was applicable for structures with vibration periods that fell in the constant velocity region of the spectra. Manfredi's input energy expression includes parameters such as pseudospectral velocity, earthquake intensity, peak ground acceleration, peak ground velocity, and a term referred to as cyclic ductility $\mu_{c}$, which is expressed as a function of the maximum cyclic plastic deformation and the yield deformation of the structure. Khashaee [16] proposed an equation for estimating seismic input energy expressed in terms of an earthquake intensity index proposed by Park and Ang [17], as well as the natural period and ductility of the structure. Other researchers who have proposed input energy spectra are Decanini and Mollaioli [18], Benavent-Climent et
TABLE 1: Soil site classification according to ASCE/SEI 7-10.

\begin{tabular}{lcc}
\hline Soil site class & Soil description & $V_{s 30}(\mathrm{~m} / \mathrm{s})$ \\
\hline B & Rock & $762<V_{s 30} \leq 1524$ \\
C & Very dense soil and soft rock & $366<V_{s 30} \leq 762$ \\
D & Stiff soil & $183<V_{s 30} \leq 366$ \\
E & Soft soil & $V_{s 30} \leq 183$ \\
\hline
\end{tabular}

$V_{s 30}$ : average shear wave velocity of the upper $30 \mathrm{~m}$ depth of soil profile of a site.

al. [19, 20], Amiri et al. [21], López-Almansa et al. [22], and Cheng et al. [23, 24].

Because of the different assumptions and methodologies used, all the aforementioned approaches that have been proposed to quantify the amount of earthquake input energy can show large variations and deviations. In addition, because most researchers used elastoplastic or bilinear hysteresis models in their computations, the accuracy of the estimates could deteriorate for structures that exhibit different kinds of hysteretic behavior. In the present study, earthquake input energy expressions that take into account ground motion characteristics, hysteretic behavior, ductility level, and soil site conditions are proposed and compared with nonlinear time history analysis results. The four hysteresis models used are shown in Figure 1. The site soil classes considered are labeled B, C, D, and E in accordance with ASCE/SEI 7-10 [25] as shown in Table 1.

3.2. Hysteretic Energy. Hysteretic energy is used as a parameter to quantify the needed energy dissipation capacity of structures subject to earthquake excitation. This is because hysteretic energy can be used to measure the inelastic cumulative damage of structures during an earthquake. Knowing the amount of energy that needs to be dissipated allows a designer to determine if a structure possesses sufficient energy dissipation capacity to avoid collapse. Hysteretic energy is the energy associated with the hysteretic behavior of a structural system and can be computed numerically by integrating the inelastic portion of the hysteretic forcedisplacement relationship of the structure under an earthquake excitation. This is equal to the area bounded by the hysteresis loops when the structure undergoes vibration under the excitation force. For a given earthquake and a SDOF system, hysteretic energy is related to input energy and can be estimated from the corresponding input energy. Its accuracy primarily depends on the accuracy of the expressions used for estimating the input energy. Unlike input energy, hysteretic energy is independent of whether relative or absolute energy is used in the energy balance equation.

One of the first researchers to propose equations for estimating hysteretic energy of SDOF systems from the corresponding input energy was Housner (1956), who defined the energy that contributed to the damage of a structure as the total seismic input energy, IE, minus the energy dissipated through inherent damping, $E_{d}$. According to this definition, the damage energy is the sum of the absorbed and kinetic energy. However, at the end of ground motion duration, the kinetic energy becomes small, and since the elastic energy 


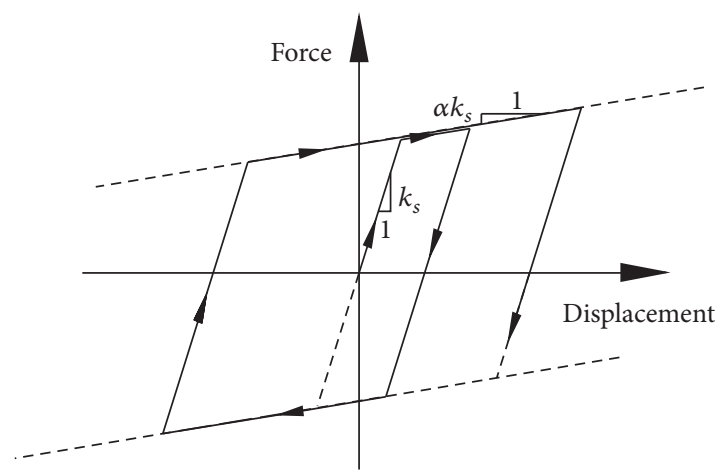

(a) Bilinear plastic

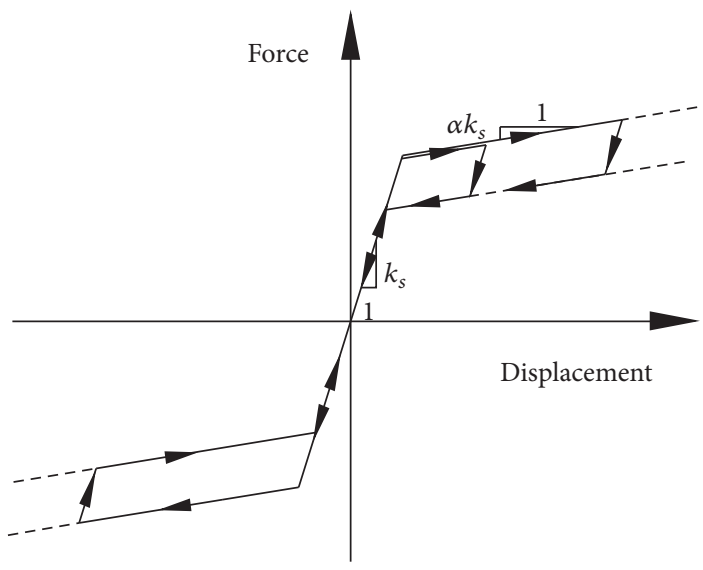

(c) Bilinear flag

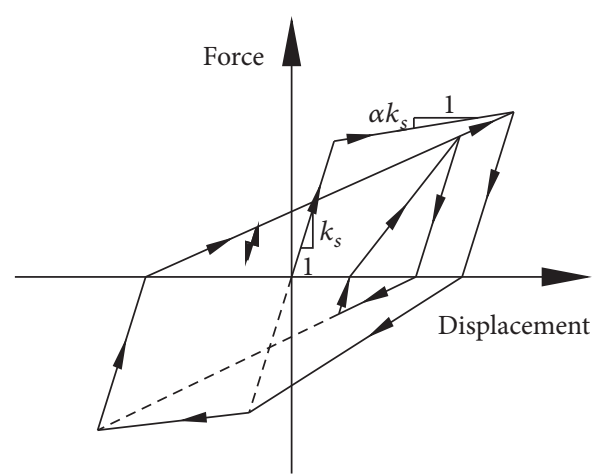

(b) Modified clough stiffness degradation

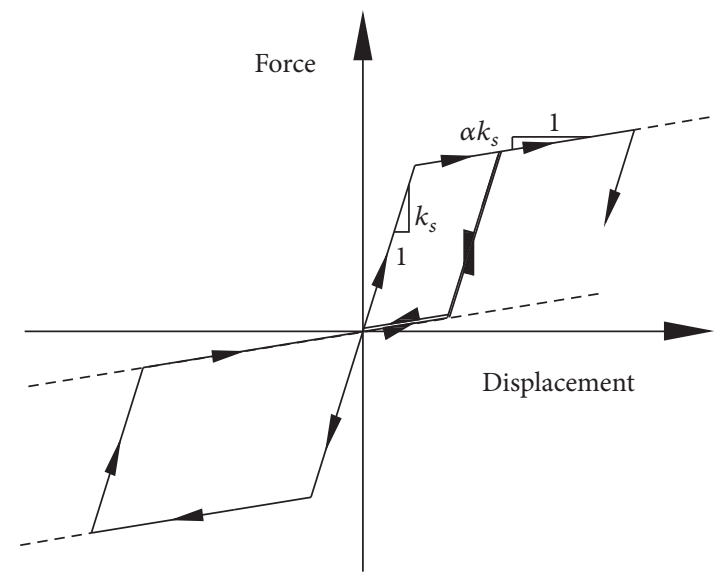

(d) Bilinear slip

FIGURE 1: Hysteresis models.

contributes only to recoverable elastic deformation, only the hysteretic energy is assumed to cause damage to the structure. Housner proposed that the ratio of damage energy per unit mass to input energy per unit mass (both have unit of velocity square) be equal to the square root of the respective energies. Akiyama (1985), based on analyses of SDOF systems with elastic-perfectly-plastic restoring force characteristics, proposed the damage to input energy per unit mass ratio as a function of the structure's damping ratio $\zeta$. Fajfar and Vidic [26] performed a parametric study on nonlinear elastoplastic SDOF systems subjected to five different ground motions from different countries and for $\zeta=0.05$ proposed an expression for the energy ratio as a function of the ductility ratio $\mu$ of the structure. For a structure with damping ratio $\zeta=0.05$, Manfredi (2001) recommended the hysteretic energy to input energy ratio be expressed as a function of the earthquake intensity, peak ground acceleration, peak ground velocity, and cyclic ductility $\mu_{c}$. Khashaee (2004), with the intention of eliminating the cyclic ductility variable used by Manfredi, applied regression analysis on input and hysteretic energies data obtained from 160 accelerograms and proposed an expression for the energy ratio which is dependent only on the ductility ratio $\mu$. López-Almansa et al. (2013), using 149 ground motion records extracted from the Turkish dataset registers classified into eight groups by soil type, surface magnitude, and source distance effects, proposed empirical criteria for estimating hysteretic energy from an input energy expressed in terms of equivalent velocity. Their study concluded that the influence of period on the hysteretic to input energy ratio was noticeable, whereas the effect of soil and ground motion parameters was observed to be negligible.

In the present work, equations that relate hysteretic to input energy that are both period and ductility dependent taking into consideration the effects of system hysteretic behavior and soil class will be presented.

\section{Ground Motion Ensembles, Target Spectra, and Hysteresis Models}

To develop the input energy spectra, four ground motion ensembles based on ASCE/SEI 7-10 (2010) site soil classes B, $\mathrm{C}, \mathrm{D}$, and $\mathrm{E}$ as shown in Table 1 are used. The numbers of earthquake records used for the four site classes are 38, 42, 38 , and 26, respectively. All these ground motion ensembles were extracted from the Pacific Earthquake Engineering Research Center (PEER) ground motion record database. They are summarized in Tables 2-5. Note that, for each selected earthquake, both the fault normal and fault parallel components were used in the study. In Tables $2-5$, the nextgeneration attenuation (NGA) number, event, year, station, moment magnitude $M_{w}$, closest distance to the rupture plane 
TABLE 2: Selected ground motion records for site class B.

\begin{tabular}{|c|c|c|c|c|c|c|c|}
\hline NGA \# & Event & Year & Station & $M_{w}$ & $R_{\text {rup }}(\mathrm{km})$ & $V_{s 30}(\mathrm{~m} / \mathrm{s})$ & Scale factor \\
\hline 2107 & Denali-Alaska & 2002 & Carlo (temp) & 7.9 & 50.9 & 963.9 & 0.8985 \\
\hline 946 & Northridge-01 & 1994 & Antelope Buttes & 6.69 & 46.9 & 821.7 & 1.7258 \\
\hline 804 & Loma Prieta & 1989 & So. San Francisco-Sierra Pt. & 6.93 & 63.1 & 1020.6 & 0.9561 \\
\hline 283 & Irpinia-Italy-01 & 1980 & Arienzo & 6.9 & 52.9 & 1000 & 2.1701 \\
\hline 1033 & Northridge-01 & 1994 & Littlerock-Brainard Can & 6.69 & 46.6 & 821.7 & 1.2158 \\
\hline 2111 & Denali-Alaska & 2002 & R109 (temp) & 7.9 & 43 & 963.9 & 0.8937 \\
\hline 1518 & Chi-Chi-Taiwan & 1999 & TCU085 & 7.62 & 58.1 & 999.7 & 1.1402 \\
\hline 788 & Loma Prieta & 1989 & Piedmont Jr High & 6.93 & 73 & 895.4 & 1.0313 \\
\hline 1587 & Chi-Chi-Taiwan & 1999 & TTN042 & 7.62 & 65.2 & 845.3 & 1.2211 \\
\hline 797 & Loma Prieta & 1989 & SF-Rincon Hill & 6.93 & 74.1 & 873.1 & 0.8949 \\
\hline 1021 & Northridge-01 & 1994 & Lake Hughes \#4-Camp Mend & 6.69 & 31.7 & 821.7 & 1.2027 \\
\hline 925 & Big Bear-01 & 1992 & Rancho Cucamonga-Deer Can & 6.46 & 59.4 & 821.7 & 2.0055 \\
\hline 1074 & Northridge-01 & 1994 & Sandberg-Bald Mtn & 6.69 & 41.6 & 821.7 & 0.8161 \\
\hline 1060 & Northridge-01 & 1994 & Rancho Cucamonga-Deer Can & 6.69 & 80 & 821.7 & 1.4735 \\
\hline 1096 & Northridge-01 & 1994 & Wrightwood-Jackson Flat & 6.69 & 64.7 & 821.7 & 1.5746 \\
\hline 2929 & Chi-Chi-Taiwan-04 & 1999 & TTN042 & 6.2 & 69 & 845.3 & 3.4843 \\
\hline 943 & Northridge-01 & 1994 & Anacapa Island & 6.69 & 68.9 & 821.7 & 2.4764 \\
\hline 795 & Loma Prieta & 1989 & SF-Pacific Heights & 6.93 & 76 & 1249.9 & 1.1371 \\
\hline 1041 & Northridge-01 & 1994 & Mt Wilson-CIT Seis Sta & 6.69 & 35.9 & 821.7 & 1.0261 \\
\hline
\end{tabular}

TABLE 3: Selected ground motion records for site class C.

\begin{tabular}{|c|c|c|c|c|c|c|c|}
\hline NGA \# & Event & Year & Station & $M_{w}$ & $R_{\text {rup }}(\mathrm{km})$ & $V_{s 30}(\mathrm{~m} / \mathrm{s})$ & Scale factor \\
\hline 299 & Irpinia-Italy-02 & 1980 & Brienza & 6.2 & 42.6 & 500 & 2.4946 \\
\hline 353 & Coalinga-01 & 1983 & Parkfield-Gold Hill 4W & 6.36 & 41.1 & 438.3 & 1.4575 \\
\hline 762 & Loma Prieta & 1989 & Fremont-Mission San Jose & 6.93 & 39.5 & 367.6 & 0.9005 \\
\hline 798 & Loma Prieta & 1989 & SF-Telegraph Hill & 6.93 & 76.5 & 712.8 & 2.182 \\
\hline 980 & Northridge-01 & 1994 & Huntington Beach-Lake St & 6.69 & 77.5 & 370.8 & 1.6481 \\
\hline 1015 & Northridge-01 & 1994 & LB-Rancho Los Cerritos & 6.69 & 51.9 & 405.2 & 1.3589 \\
\hline 1026 & Northridge-01 & 1994 & Lawndale-Osage Ave & 6.69 & 39.9 & 361.2 & 0.9721 \\
\hline 1027 & Northridge-01 & 1994 & Leona Valley \#1 & 6.69 & 37.2 & 684.9 & 1.5469 \\
\hline 1028 & Northridge-01 & 1994 & Leona Valley \#2 & 6.69 & 37.2 & 446 & 1.4716 \\
\hline 1029 & Northridge-01 & 1994 & Leona Valley \#3 & 6.69 & 37.3 & 684.9 & 1.3395 \\
\hline 1190 & Chi-Chi-Taiwan & 1999 & CHY019 & 7.62 & 50.5 & 478.3 & 1.6949 \\
\hline 1284 & Chi-Chi-Taiwan & 1999 & HWA035 & 7.62 & 48.4 & 500.8 & 1.3759 \\
\hline 1594 & Chi-Chi-Taiwan & 1999 & TTN051 & 7.62 & 36.7 & 680 & 2.8355 \\
\hline 2609 & Chi-Chi-Taiwan-03 & 1999 & TCU053 & 6.2 & 40.6 & 454.6 & 3.0711 \\
\hline 2714 & Chi-Chi-Taiwan-04 & 1999 & CHY046 & 6.2 & 38.1 & 442.1 & 0.9412 \\
\hline 2916 & Chi-Chi-Taiwan-04 & 1999 & TTN022 & 6.2 & 56.3 & 507 & 3.0915 \\
\hline 2952 & Chi-Chi-Taiwan-05 & 1999 & CHY042 & 6.2 & 67.7 & 680 & 2.4116 \\
\hline 3202 & Chi-Chi-Taiwan-05 & 1999 & TCU102 & 6.2 & 52.8 & 714.3 & 2.3519 \\
\hline 3224 & Chi-Chi-Taiwan-05 & 1999 & TTN001 & 6.2 & 59.2 & 424 & 2.6425 \\
\hline 3447 & Chi-Chi-Taiwan-06 & 1999 & TCU032 & 6.3 & 59.6 & 454.4 & 2.7129 \\
\hline 3495 & Chi-Chi-Taiwan-06 & 1999 & TCU109 & 6.3 & 37.9 & 424.2 & 1.1679 \\
\hline
\end{tabular}

$R_{\text {rup }}$, average shear wave velocity of the upper $30 \mathrm{~m}$ depth of soil profile $V_{s 30}$, and scale factor (discussed in the section on Target Spectra) are given. Additional information on these ground motion records can be found in http://peer.berkeley .edu/products/strong_ground_motion_db.html. Some general comments in regard to earthquake magnitudes, site-tosource distances, target spectra, and damping used in the present study are given below.
4.1. Earthquake Magnitudes. The ground motion records have moment magnitudes $M_{w}$ that vary from 6.2 to 7.9 . This range covers ground motions referred to as strong to major earthquakes.

4.2. Site-to-Source Distances $(\mathrm{km})$. The effect of near-source ground motions on structures is more pronounced compared to that of far-source ground motions. Hall et al. [27], 
TABLE 4: Selected ground motion records for site class D.

\begin{tabular}{|c|c|c|c|c|c|c|c|}
\hline NGA \# & Event & Year & Station & $M_{w}$ & $R_{\text {rup }}(\mathrm{km})$ & $V_{s 30}(\mathrm{~m} / \mathrm{s})$ & Scale factor \\
\hline 3271 & Chi-Chi-Taiwan-06 & 1999 & CHY032 & 6.3 & 65 & 192.7 & 1.2106 \\
\hline 1816 & Hector Mine & 1999 & North Palm Springs Fire Sta \#36 & 7.13 & 61.8 & 345.4 & 1.9373 \\
\hline 3276 & Chi-Chi-Taiwan-06 & 1999 & CHY037 & 6.3 & 53.7 & 212.1 & 1.0657 \\
\hline 2695 & Chi-Chi-Taiwan-04 & 1999 & CHY016 & 6.2 & 79.8 & 200.9 & 2.9223 \\
\hline 832 & Landers & 1992 & Amboy & 7.28 & 69.2 & 271.4 & 0.9457 \\
\hline 1177 & Kocaeli-Turkey & 1999 & Zeytinburnu & 7.51 & 53.9 & 274.5 & 1.3668 \\
\hline 1290 & Chi-Chi-Taiwan & 1999 & HWA043 & 7.62 & 58 & 228.6 & 2.3407 \\
\hline 1637 & Manjil-Iran & 1990 & Rudsar & 7.37 & 64.5 & 274.5 & 1.3285 \\
\hline 862 & Landers & 1992 & Indio-Coachella Canal & 7.28 & 54.2 & 345.4 & 1.3058 \\
\hline 3313 & Chi-Chi-Taiwan-06 & 1999 & CHY094 & 6.3 & 59.6 & 221.9 & 2.0942 \\
\hline 941 & Big Bear-01 & 1992 & Yermo Fire Station & 6.46 & {$[71.0]$} & 353.6 & 2.7963 \\
\hline 907 & Big Bear-01 & 1992 & Hesperia-4th \& Palm & 6.46 & {$[44.8]$} & 345.4 & 2.2741 \\
\hline 3265 & Chi-Chi-Taiwan-06 & 1999 & CHY025 & 6.3 & 40.3 & 277.5 & 1.1293 \\
\hline 958 & Northridge-01 & 1994 & Camarillo & 6.69 & 40.3 & 234.9 & 1.1067 \\
\hline 3480 & Chi-Chi-Taiwan-06 & 1999 & TCU086 & 6.3 & 64.2 & 222.2 & 2.7385 \\
\hline 1762 & Hector Mine & 1999 & Amboy & 7.13 & 43 & 271.4 & 0.7422 \\
\hline 1791 & Hector Mine & 1999 & Indio-Coachella Canal & 7.13 & 73.5 & 345.4 & 1.6048 \\
\hline 1776 & Hector Mine & 1999 & Desert Hot Springs & 7.13 & 56.4 & 345.4 & 2.1505 \\
\hline 2720 & Chi-Chi-Taiwan-04 & 1999 & CHY056 & 6.2 & 79.4 & 193 & 2.5407 \\
\hline
\end{tabular}

TABLE 5: Selected ground motion records for site class E.

\begin{tabular}{|c|c|c|c|c|c|c|c|}
\hline NGA \# & Event & Year & Station & $M_{w}$ & $R_{\text {rup }}(\mathrm{km})$ & $V_{s 30}(\mathrm{~m} / \mathrm{s})$ & Scale factor \\
\hline 3319 & Chi-Chi- Taiwan-06 & 1999 & CHY107 & 6.3 & 79.8 & 175.7 & 1.8138 \\
\hline 962 & Northridge-01 & 1994 & Carson-Water St & 6.69 & 49.8 & 160.6 & 1.903 \\
\hline 1147 & Kocaeli-Turkey & 1999 & Ambarli & 7.51 & 69.6 & 175 & 0.7059 \\
\hline 1229 & Chi-Chi-Taiwan & 1999 & CHY078 & 7.62 & 77.2 & 160.7 & 2.3854 \\
\hline 3285 & Chi-Chi-Taiwan-06 & 1999 & CHY054 & 6.3 & 77.6 & 172.1 & 1.9532 \\
\hline 2736 & Chi-Chi-Taiwan-04 & 1999 & CHY076 & 6.2 & 56.4 & 169.8 & 5.6455 \\
\hline 3302 & Chi-Chi-Taiwan-06 & 1999 & CHY076 & 6.3 & 70.4 & 169.8 & 1.4669 \\
\hline 2510 & Chi-Chi-Taiwan-03 & 1999 & CHY107 & 6.2 & 72.5 & 175.7 & 2.8682 \\
\hline 1212 & Chi-Chi-Taiwan & 1999 & CHY054 & 7.62 & 48.5 & 172.1 & 1.3432 \\
\hline 2476 & Chi-Chi-Taiwan-03 & 1999 & CHY054 & 6.2 & 70.4 & 172.1 & 2.8264 \\
\hline 808 & Loma Prieta & 1989 & Treasure Island & 6.93 & 77.4 & 155.1 & 1.0323 \\
\hline 2755 & Chi-Chi-Taiwan-04 & 1999 & CHY107 & 6.2 & 63.4 & 175.7 & 2.7405 \\
\hline 2718 & Chi-Chi-Taiwan-04 & 1999 & CHY054 & 6.2 & 61.1 & 172.1 & 2.6975 \\
\hline
\end{tabular}

Campbell [28], and Bazzurro and Luco [29] have suggested that pronounced effects of near-source ground motions need to be addressed differently during design. In other words, the result of a study based on a mix of near-source and farsource ground motion records is likely to give misleading conclusions. As a result, this study has excluded near-source ground motion records in the selected ground motion ensemble and is primarily focused on far-source ground motion effects. Near-source and far-source ground motion records are considered to have an epicentral distance of less than $15 \mathrm{~km}$ and greater than $30 \mathrm{~km}$, respectively, to the site of the structure or recording station. In this study, the epicentral distance of the selected ground motions spans the range of approximately 30 to $80 \mathrm{~km}$.
4.3. Target Spectra. In developing design spectra, it is desirable to have the group of selected ground motion records exhibit similar spectral characteristics. The resulting design spectra developed using such similar spectra should yield smaller standard deviation. However, because ground motions that occur at different sites have different magnitudes, peak values, and durations and when averaged, the resulting standard deviations could still be high. To minimize the anticipated high discrepancies and variations, ground motions are often scaled to match some target spectra before they are used in time history analysis. In this study, ground motion records were selected and scaled to match soil sitebased response spectra generated by geometrically combining the Pacific Earthquake Engineering Research Center's 


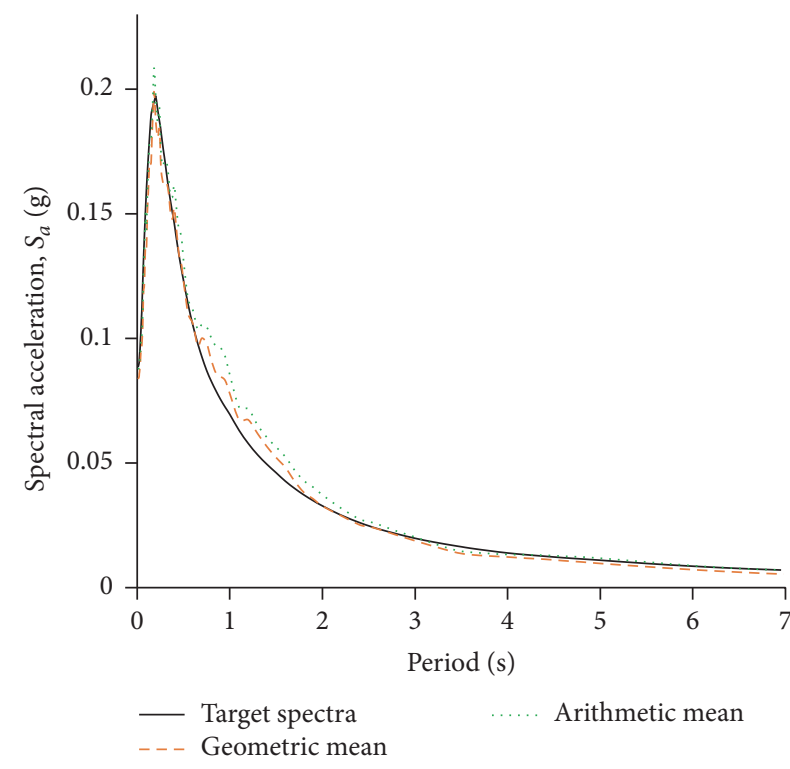

(a) Soil site class B

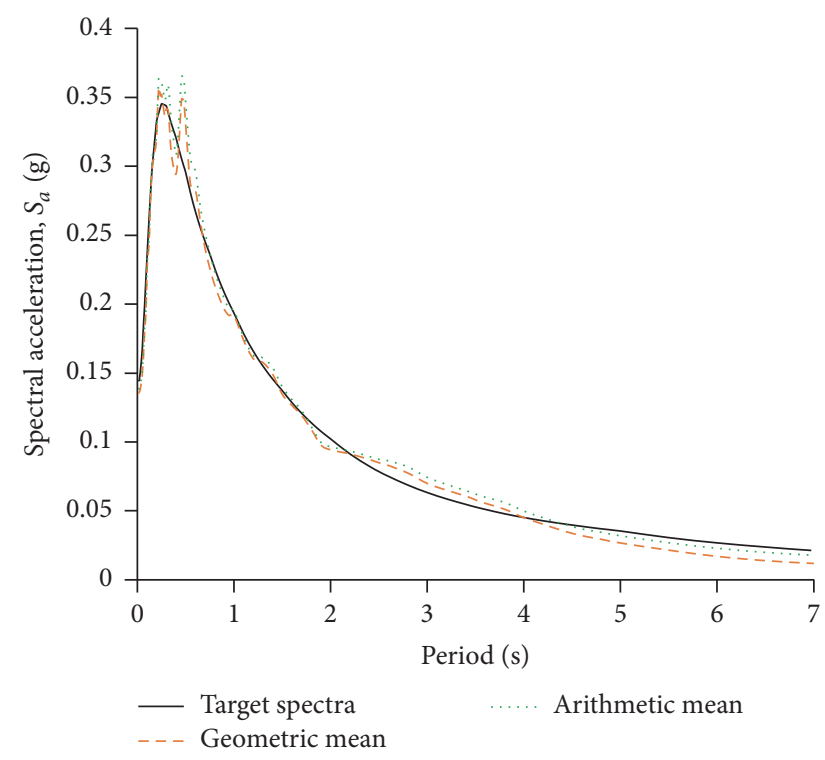

(c) Soil site class D

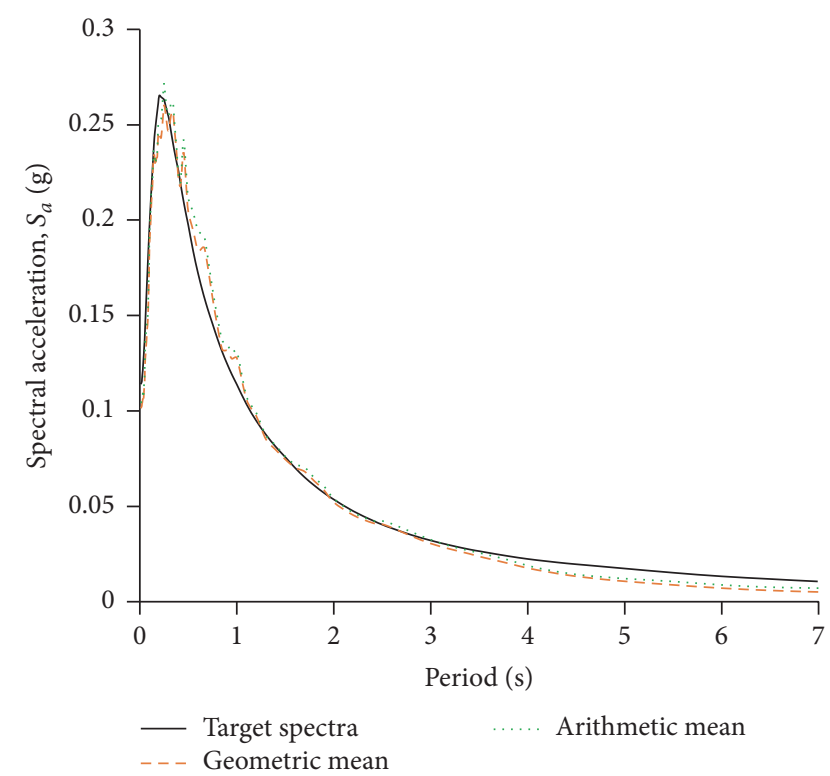

(b) Soil site class C

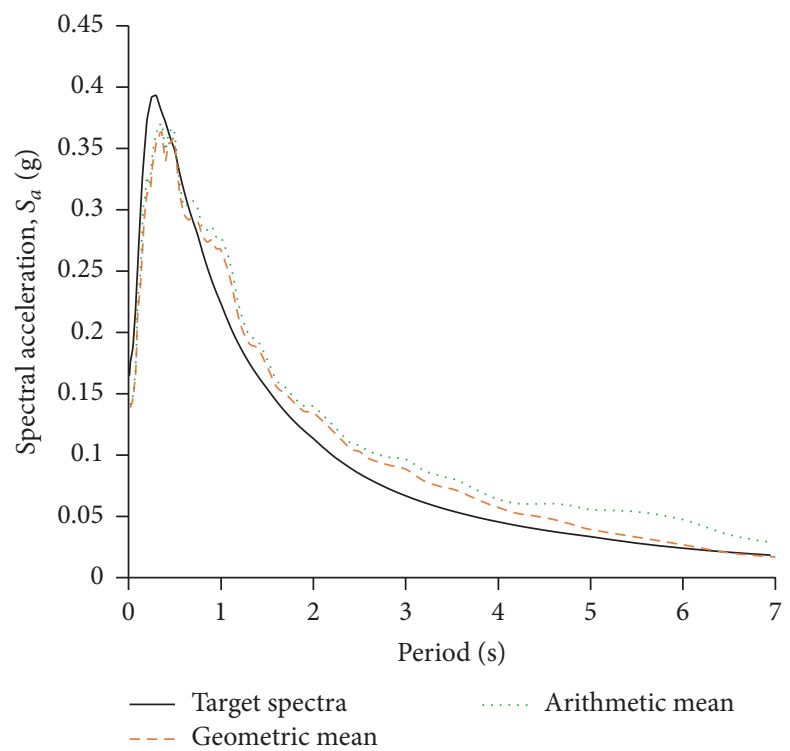

(d) Soil site class E

FIgURE 2: Target and mean spectra for different soil site classes.

Next Generation Attenuation (PEER-NGA) ground motion models developed by Abrahamson and Silva [30], Campbell and Bozorgnia [31], Boore and Atkinson [32], and Chiou and Youngs [33] so they represent an 84th percentile (i.e., one standard deviation above the mean values) of the geometric mean of these four attenuation models. The target spectra for the four soil site classes are shown in Figure 2. Also shown in this figure are the geometric and arithmetic means of the ensembles of earthquake spectra generated from the selected earthquake records for each respective soil site class. The parity between the mean and target spectra indicates that the selected ground motion records satisfactorily represent ground motions recorded at each specific soil site class. A statistical analysis yields a correlation coefficient of 0.99 , which signifies that each selected ground motion ensemble is a good representative of its respective soil site class. The selection and scaling of all the ground motions have been made in such a way that the resulting ground motion spectra match the target spectra in the period range 0.1 to $3.5 \mathrm{~s}$ with equal weights. This range of vibration periods was chosen because most medium- to high-rise buildings have fundamental periods of vibrations of 0.3 to $3.0 \mathrm{~s}$ according to the PEER manual, and most bridges have fundamental periods of vibrations in the 0.2 to $1.2 \mathrm{~s}$ range according to Kunde and Jangid [34].

4.4. Damping. In the USA, the design of earthquake-resistant structures is often based on a damping ratio of $5 \%$ as seismic 
design maps contained in ASCE/SEI 7-10 (2010) and IBC [35] for building design and AASHTO [36] for bridge design were all developed based on $5 \%$ of critical damping. It is also common to use 5\% damping to capture the damping behavior of structures that exhibit inelastic behavior when subjected to dynamic loading. Thus, a damping value of $5 \%$ was used in this study to develop the site class and hysteretic specific input energy spectra.

4.5. Ductility. Ductility plays an important role in the response of structures to dynamic loading. The more ductile the structure is, the less likely it will experience catastrophic damage during a major seismic event. Constant ductility spectra developed by Peng and Conte [37], Inel et al. [38], and Zhai and Xie [39] supported the same hypothesis. According to Chopra and Goel [40], constant ductility spectra are being used more often for seismic design. In view of this, the input energy spectra developed in this study are chosen to be constant ductility spectra with ductility levels of $\mu=1,2,3,4$ and 5. Note that $\mu=1$ means the structure remains elastic.

4.6. Hysteresis Models. The force-displacement relationship or hysteretic behavior of a structure affects its seismic response and hence the energy spectra. Thus, it is important that the hysteretic behavior of a structure being designed is known and considered in the determination of the input energy. In this study, four different hysteresis models, namely, bilinear plastic (BP), stiffness degradation or modified clough (SD), bilinear flag (BF), and bilinear slip (BS) as shown in Figure 1, are considered. The BP model is often used to model the cyclic behavior of steel structures with strain hardening effect, while the SD model is used to model reinforced concrete structures that exhibit stiffness degradation under repeated loading and unloading [41]. The BF model is generally used for modeling structures that are capable of recentering after an earthquake $[42,43]$, and the BS model is used to model structures that experience joint or bond slippage [44]. In the figure, $k_{s}$ is the initial stiffness, which changes in accordance with the period of the SDOF system, but a constant post- to preyield stiffness ratio of $\alpha=0.05$ is used because real structures do not undergo complete plastification after first yield. The effect of the value of $\alpha$ on the shape or size of the input energy spectra is not very significant. For instance, Nakashima et al. [45] studied bilinear SDOF and MDOF structures with post- to preyield stiffness ratio up to 0.75 and concluded the effects of $\alpha$ only have a minor effect on the input energy.

\section{Energy Spectra and Normalization Parameter}

Using the scaled ground motion records and hysteresis models, nonlinear time history analyses were performed and (7) was numerically integrated to generate constant ductility spectra with damping ratio $\zeta=5 \%$. In addition to accounting for structural properties (hysteresis model, period, ductility, and damping) and soil site effects, it is desirable to consider the effect of earthquake intensity in the development of the proposed energy spectra. One way to incorporate the earthquake intensity effect is to normalize the energy spectra using some seismic damage indices or quantities that are used to measure the intensity of seismic events. In the present study, the following ground motion indices have been used to determine this normalization parameter.

(i) Cumulative absolute velocity (CAV) (EPRC [46]):

$$
\mathrm{CAV}=\int_{0}^{t}\left|\ddot{u}_{g}(t)\right| d t .
$$

(ii) Arias intensity $\left(I_{A}\right)$ (Arias [47]):

$$
I_{A}=\frac{\pi}{2 g} \int_{0}^{t} \ddot{u}_{g}^{2}(t) d t .
$$

(iii) Seismic damage index $\left(I_{d}\right)$ (Manfredi (2001)):

$$
I_{d}=\frac{1}{\mathrm{PGA} \times \mathrm{PGV}} \int_{0}^{t} \ddot{u}_{g}^{2}(t) d t .
$$

(iv) Velocity index (VI) (proposed in the present study):

$$
\mathrm{VI}=\mathrm{CAV} \times \mathrm{PGV}
$$

where $\ddot{u}_{g}(t)$ is ground motion acceleration, $g$ is acceleration due to gravity $=9.81 \mathrm{~m} / \mathrm{s}^{2}\left(32.2 \mathrm{ft} / \mathrm{s}^{2}\right)$, PGA is peak ground acceleration, $\mathrm{PGV}$ is peak ground velocity, and $t$ is duration of ground motion.

Applying the above indices as normalization parameters, the coefficients of variation for various periods and ductility ratios calculated from the suite of earthquake records for soil site class B and bilinear plastic (BP) hysteresis model are plotted in Figure 3. As can be seen, the coefficients of variation for the input energy per unit mass normalized by the proposed velocity index are the lowest for the range of periods and ductility used. Similar observations are made for other soil site classes and hysteresis models. It should be noted that a key advantage of CAV over other peak ground motion and response-spectral parameters is that through integration of the absolute value of the ground acceleration, it can account for the cumulative effect of the ground motion duration. According to EPRC (1998), CAV is also a ground motion parameter that best correlated with structural damage out of the various ground motion parameters that it investigated. One shortcoming of CAV is that although it has unit of velocity, it is not directly related to the ground motion velocity, so some characteristics of the ground motion are lost. By combining both CAV and PGV into a single parameter VI, we are able to take advantage of the desirable characteristics of both parameters. Hence, the proposed velocity index will be used as the normalization parameter for all subsequent computations. Note that the unit of VI is (distance/time) ${ }^{2}$, which is the same as that of energy per unit mass. Thus, normalization of the input energy per unit mass by VI results in an energy spectrum that is nondimensional. Nondimensional spectra have an added advantage that they allow designers to use any units of their choice. Moreover, for a given seismic site and soil class, the 

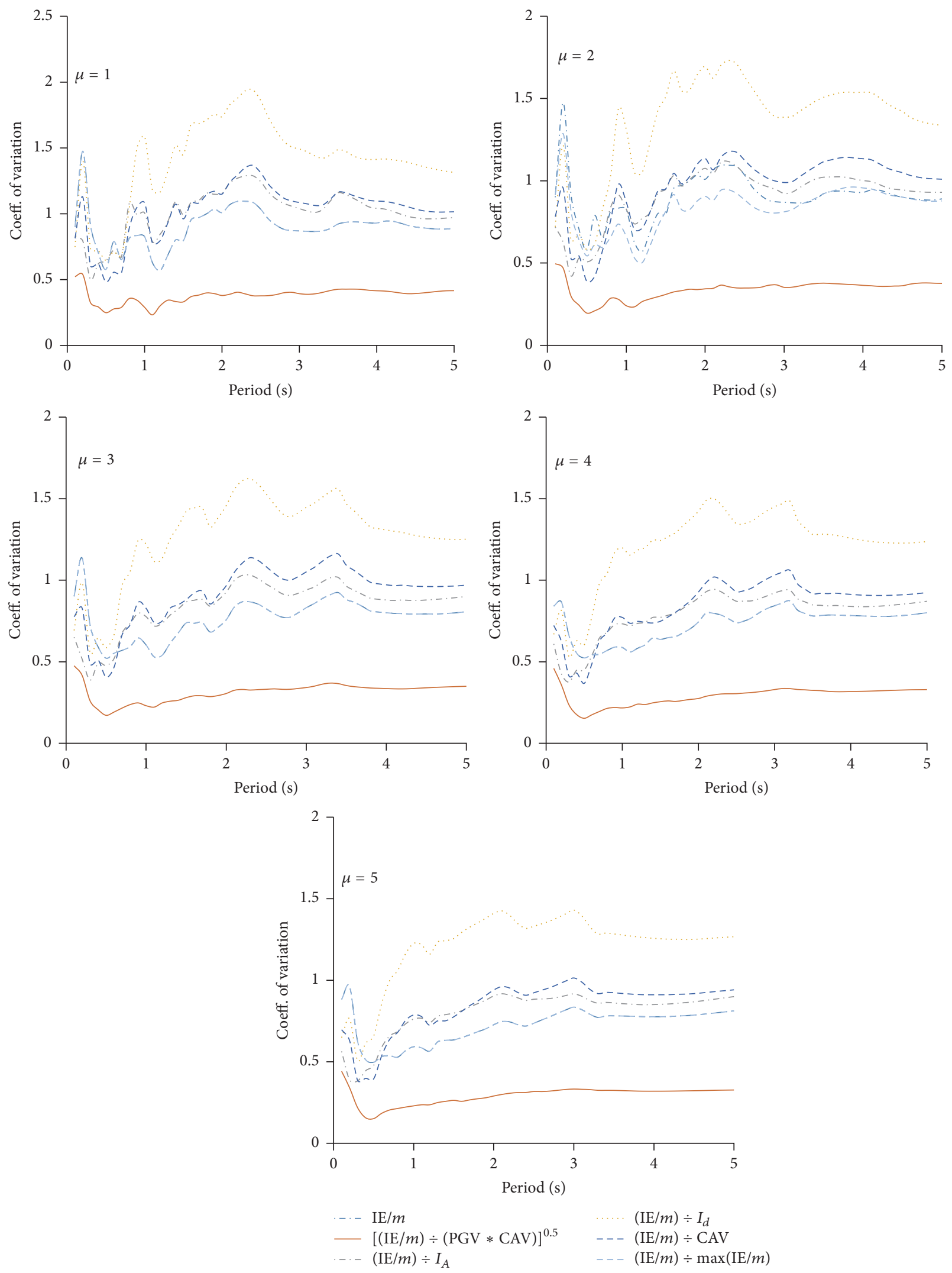

FIGURE 3: Coefficient of variation for hysteresis model BP. 
two quantities PGV and CAV required to calculate VI can readily be obtained from the literature. Publications by Power et al. [48], Campbell and Bozorgnia [49], and Bradley [50] are among some research findings that give CAV and PGV prediction equations.

\section{Proposed Normalized Energy Spectra}

Nonlinear analysis software called BISPEC [51] was used to obtain input energy (IE) and hysteretic energy (HE) spectral values of SDOF systems. The spectral values were obtained from nonlinear time history analysis of an SDOF system subjected to earthquake ground motion records by using the widely used Newmark integration method. In this study, values of beta $(\beta)=1 / 4$ and gamma $(\gamma)=1 / 2$ (i.e., the average acceleration method) were used. Time steps for all the analyses were taken as the minimum of three quantities: (1) the recorded earthquake time step, (2) the period of the SDOF divided by 25 , and (3) $0.01 \mathrm{~s}$. Once the input energy spectral values were obtained, they were normalized as discussed below.

The normalized energy (NE) proposed in this study is defined as the square root of the input energy per unit mass, $\mathrm{IE} / m$, divided by the velocity index, VI; that is,

$$
\mathrm{NE}=\sqrt{\frac{\mathrm{IE} / m}{\mathrm{VI}}}=\sqrt{\frac{\mathrm{IE} / m}{\mathrm{CAV} \times \mathrm{PGV}}} .
$$

The use of (12) as a normalization parameter not only converts the input energy per unit mass to a nondimensional quantity but also makes the energy spectra more narrowly banded (i.e., relatively smaller peaks and valleys) when compared with the actual input energy spectra. This is demonstrated in Figure 4 where the actual input energy spectra, $\mathrm{IE} / m$, (Figure 4(a)) are compared with the VI normalized input energy spectra (NE) (Figure 4(b)) for SDOF structures with hysteresis model $\mathrm{BP}$, ductility ratios of $\mu=1,2,3,4,5$, and soil site class B. The figure clearly shows that, upon normalization by VI, the peaks and valleys of the input energy spectra are less pronounced, thus reducing the dispersion of the spectral values. Also shown in Figure 4 are the mean $+\sigma$ and mean $+2 \sigma$ spectra, which can be seen as enveloping a rather high percentage of the input energy spectra for the selected ground motion records, particularly in the range of periods from 0.5 to $5 \mathrm{~s}$. Similar observations have been made for the other three hysteresis models and soil site classes investigated in this study. It should be noted that the use of the mean $+\sigma$ or mean $+2 \sigma$ spectra as opposed to the mean spectra is recommended for use in the proposed EBSD not only because they envelope a relatively high percentage of the input energy spectra but also because the potential damage caused by the kinetic energy component of the input energy is ignored and so a more conservative approach is warranted.

The equations used to represent the mean $+\sigma$ and mean $+2 \sigma$ VI normalized input energy spectra are to be derived so they will conform to the general shape of design spectra often used in seismic codes. That is, they will consist of three regions: (1) a straight line for structures in the short period range, (2) a constant (plateau) for structures in the intermediate period range, and (3) a power curve for structures in the long period range. Thus, the proposed VI normalized input energy spectra, NE, in the period range $0<T \leq 5 \mathrm{~s}$ will have the following form.

$$
\mathrm{NE}= \begin{cases}a T+b ; & 0<T \leq T_{1} \\ C ; & T_{1}<T \leq T_{2} \\ k T^{n} ; & T_{2}<T \leq 5 \mathrm{~s}\end{cases}
$$

where, with reference to Figure 5 , the constants $a$ and $b$ define the linear part of the spectra, $C$ is the maximum value of the NE spectra, and $T_{1}$ and $T_{2}$ are the periods that separate the short and long period regions from the intermediate region of the spectra.

Values of $a, b, C, k, n, T_{1}$, and $T_{2}$ for the SDOF normalized energy (NE) spectra are obtained for the four site classes and four hysteresis models using a three-part nonlinear regression analysis: one each for the short, intermediate, and long period regions. They are then expressed as a function of ductility as shown in Tables 6-9.

In accordance with (12), the corresponding input energy per unit mass $(\mathrm{IE} / \mathrm{m})$ spectra for a given hysteresis model, soil site class, and a design ductility level can now be obtained by multiplying the square of the ordinates of the proposed normalized energy (NE) spectra by the VI values; that is,

$$
\begin{aligned}
\text { mean }+\sigma\left(\frac{\mathrm{IE}}{m}\right)= & \{\text { mean }+\sigma(\mathrm{NE})\}^{2} \\
& \times\{\text { mean }+\sigma(\mathrm{VI})\} \\
\text { mean }+2 \sigma\left(\frac{\mathrm{IE}}{m}\right)= & \{\text { mean }+2 \sigma(\mathrm{NE})\}^{2} \\
& \times\{\text { mean }+2 \sigma(\mathrm{VI})\}
\end{aligned}
$$

The resulting IE/ $m$ spectra are plotted in Figures $6-9$ as curves labelled proposed mean $+\sigma$ and proposed mean $+2 \sigma$.

Overall, the following general trends were observed. (1) The maximum input energy spectral value increases from soil site class B (rock) to D (stiff soil) regardless of the hysteresis model. This trend is in agreement with the soil site effect on elastic design spectrum described in ASCE/SEI 7-10 (2010). A similar trend was also reported by Decanini and Mollaioli (1998) and López-Almansa et al. (2013). (2) The effect of hysteretic behavior on input energy is not quite distinctive. (3) The effect of ductility level on the input energy spectral values is more pronounced at lower levels of ductility but diminishes as ductility increases. For instance, for site class $\mathrm{C}$ and hysteresis model SD, the decreases in spectral value in the constant region of the normalized mean $+\sigma$ energy spectra between two successive ductility levels $\mu=1 \& 2$, $\mu=2 \& 3, \mu=3 \& 4$, and $\mu=4 \& 5$ are $10 \%, 3 \%, 3 \%$, and $1 \%$, respectively. The corresponding values for the mean $+2 \sigma$ spectra are $15 \%, 3.5 \%, 3.5 \%$, and $1 \%$. This finding is in line with what was reported by López-Almansa et al. (2013) where they concluded that, in the intermediate and long period regions, the input energy spectra are mainly dependent on period and are not particularly sensitive to nonlinearity (i.e., ductility). 

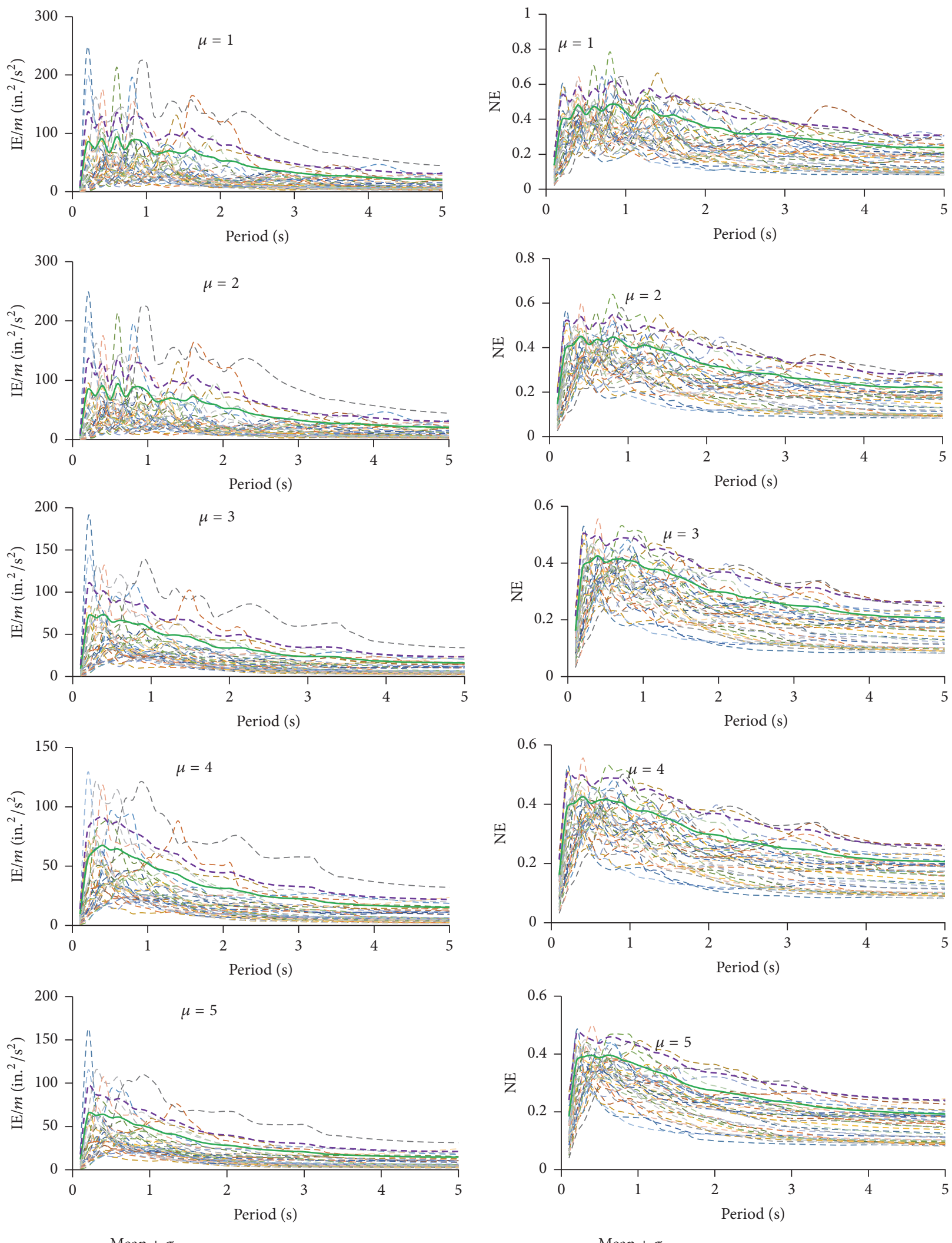

- Mean $+\sigma$
--- Mean $+2 \sigma$

- - Mean $+2 \sigma$

(a)

(b)

FIGURE 4: Comparison of actual (IE/m) and VI normalized input energy (NE) spectra. 


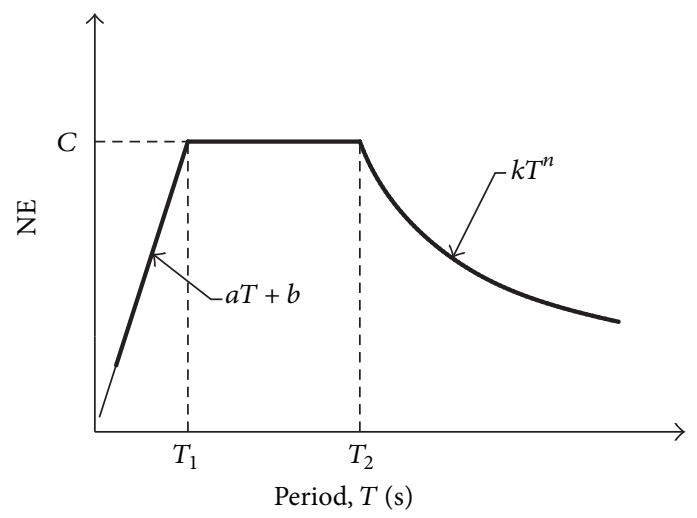

FIGURE 5: Proposed normalized input energy spectra.

TABLE 6: Normalized input energy spectral shape parameters (site class B).

\begin{tabular}{|c|c|c|}
\hline & Mean $+\sigma$ & Mean $+2 \sigma$ \\
\hline \multicolumn{3}{|c|}{ Hysteresis model BP } \\
\hline$a$ & $-0.181 \mu+2.785$ & $-0.319 \mu+3.826$ \\
\hline$b$ & $0.0301 \mu-0.154$ & $0.0463 \mu-0.214$ \\
\hline$T_{1}(\mathrm{~s})$ & $0.233 \mu^{-0.054}$ & $0.220 \mu^{-0.066}$ \\
\hline C & $-0.0217 \mu+0.498$ & $0.0104 \mu^{2}-0.0973 \mu+0.699$ \\
\hline$T_{2}(\mathrm{~s})$ & $1.285 \mu^{-0.217}$ & $1.333 \mu^{-0.228}$ \\
\hline$k$ & $0.0092 \mu^{2}-0.0969 \mu+0.636$ & $0.015 \mu^{2}-0.152 \mu+0.834$ \\
\hline$n$ & $-0.0039 \mu^{2}+0.0484 \mu-0.564$ & $-0.006 \mu^{2}+0.0674 \mu-0.574$ \\
\hline \multicolumn{3}{|c|}{ Hysteresis model SD } \\
\hline$a$ & $-0.335 \mu+2.816$ & $-0.552 \mu+3.845$ \\
\hline$b$ & $0.063 \mu-0.164$ & $0.091 \mu-0.224$ \\
\hline$T_{1}(\mathrm{~s})$ & $0.232 \mu^{-0.059}+0.001$ & $0.219 \mu^{-0.056}+0.004$ \\
\hline C & $0.0069 \mu^{2}-0.0624 \mu+0.536$ & $0.0126 \mu^{2}-0.111 \mu+0.702$ \\
\hline$T_{2}(\mathrm{~s})$ & $-0.108 \mu+1.323$ & $-0.0975 \mu+1.364$ \\
\hline$k$ & $0.0119 \mu^{2}-0.114 \mu+0.64$ & $0.0175 \mu^{2}-0.164 \mu+0.828$ \\
\hline$n$ & $-0.0085 \mu^{2}+0.0766 \mu-0.576$ & $-0.0108 \mu^{2}+0.0929 \mu-0.58$ \\
\hline \multicolumn{3}{|c|}{ Hysteresis model BF } \\
\hline$a$ & $-0.202 \mu+2.848$ & $-0.367 \mu+3.947$ \\
\hline$b$ & $0.0343 \mu-0.163$ & $-0.055 \mu-0.231$ \\
\hline$T_{1}(\mathrm{~s})$ & $0.232 \mu^{-0.025}$ & $0.218 \mu^{-0.028}+0.01$ \\
\hline C & $0.485 \mu^{-0.085}+0.003$ & $0.612 \mu^{-0.134}$ \\
\hline$T_{2}(\mathrm{~s})$ & $1.284 \mu^{-0.25}$ & $1.276 \mu^{-0.169}+0.08$ \\
\hline$k$ & $-0.0372 \mu+0.565$ & $0.687 \mu^{-0.216}$ \\
\hline$n$ & $-0.0051 \mu^{2}+0.0057 \mu-0.559$ & $-0.0081 \mu^{2}+0.0764 \mu-0.560$ \\
\hline \multicolumn{3}{|c|}{ Hysteresis model BS } \\
\hline$a$ & $2.631 \mu^{-0.469}$ & $3.575 \mu^{-0.624}$ \\
\hline$b$ & $0.0644 \mu-0.148$ & $0.09 \mu-0.198$ \\
\hline$T_{1}(\mathrm{~s})$ & $0.234 \mu^{-0.048}+0.02$ & $0.217 \mu^{-0.01}+0.01$ \\
\hline C & $0.481 \mu^{-0.102}+0.003$ & $0.596 \mu^{-0.13}+0.015$ \\
\hline$T_{2}(\mathrm{~s})$ & $1.261 \mu^{-0.335}+0.08$ & $1.324 \mu^{-0.349}+0.08$ \\
\hline$k$ & $0.0107 \mu^{2}-0.106 \mu+0.63$ & $0.0176 \mu^{2}-0.161 \mu+0.82$ \\
\hline$n$ & $-0.0135 \mu^{2}+0.111 \mu-0.598$ & $-0.0187 \mu^{2}+0.152 \mu-0.622$ \\
\hline
\end{tabular}


TABLE 7: Normalized input energy spectral shape parameters (site class C).

\begin{tabular}{|c|c|c|}
\hline & Mean $+\sigma$ & Mean $+2 \sigma$ \\
\hline \multicolumn{3}{|c|}{ Hysteresis model BP } \\
\hline$a$ & $-0.0507 \mu+1.515$ & $-0.0873 \mu+1.757$ \\
\hline$b$ & $0.0137 \mu-0.0569$ & $0.0172 \mu-0.0569$ \\
\hline$T_{1}(\mathrm{~s})$ & $0.374 \mu^{-0.116}$ & $0.389 \mu^{-0.113}$ \\
\hline C & $\begin{array}{c}0.0069 \mu^{2}-0.0657 \mu+ \\
0.563\end{array}$ & $0.0115 \mu^{2}-0.106 \mu+0.711$ \\
\hline$T_{2}(\mathrm{~s})$ & $-0.102 \mu+1.978$ & $-0.108 \mu+2.02$ \\
\hline$k$ & $0.0089 \mu^{2}-0.129 \mu+0.946$ & $0.0205 \mu^{2}-0.232 \mu+1.253$ \\
\hline$n$ & $\begin{array}{c}0.0072 \mu^{2}-0.0124 \mu- \\
0.786\end{array}$ & $0.0031 \mu^{2}+0.02 \mu-0.838$ \\
\hline \multicolumn{3}{|c|}{ Hysteresis model SD } \\
\hline$a$ & $0.0218 \mu^{2}-0.175 \mu+1.601$ & $0.0416 \mu^{2}-0.321 \mu+1.927$ \\
\hline$b$ & $0.0255 \mu-0.0547$ & $-0.0069 \mu^{2}+0.0699 \mu-0.0969$ \\
\hline$T_{1}(\mathrm{~s})$ & $0.379 \mu^{-0.164}$ & $0.34 \mu^{-0.174}$ \\
\hline C & $0.007 \mu^{2}-0.0601 \mu+0.555$ & $0.0128 \mu^{2}-0.108 \mu+0.709$ \\
\hline$T_{2}(\mathrm{~s})$ & $-0.191 \mu+1.959$ & $-0.2 \mu+1.995$ \\
\hline$k$ & $0.023 \mu^{2}-0.222 \mu+0.983$ & $0.0345 \mu^{2}-0.318 \mu+1.237$ \\
\hline$n$ & $0.0468 \mu-0.784$ & $-0.0082 \mu^{2}+0.0955 \mu-0.809$ \\
\hline \multicolumn{3}{|c|}{ Hysteresis model BF } \\
\hline$a$ & $0.0223 \mu^{2}-0.142 \mu+1.585$ & $0.0406 \mu^{2}-0.27 \mu+1.908$ \\
\hline$b$ & $\begin{array}{c}-0.0022 \mu^{2}+0.0226 \mu- \\
0.0636\end{array}$ & $-0.0037 \mu^{2}+0.0335 \mu-0.0691$ \\
\hline$T_{1}(\mathrm{~s})$ & $-0.016 \mu+0.392$ & $-0.0028 \mu^{2}+0.0001 \mu+0.394$ \\
\hline C & $\begin{array}{c}0.0043 \mu^{2}-0.0427 \mu+ \\
0.543\end{array}$ & $0.0071 \mu^{2}-0.0685 \mu+0.677$ \\
\hline$T_{2}(\mathrm{~s})$ & $-0.151 \mu+1.952$ & $-0.159 \mu+1.993$ \\
\hline$k$ & $0.0163 \mu^{2}-0.174 \mu+0.959$ & $0.03 \mu^{2}-0.286 \mu+1.268$ \\
\hline$n$ & $0.0437 \mu-0.802$ & $-0.792 \mu^{-0.218}$ \\
\hline \multicolumn{3}{|c|}{ Hysteresis model BS } \\
\hline$a$ & $0.0326 \mu+1.420$ & $0.037 \mu+1.617$ \\
\hline$b$ & $\begin{array}{c}-0.0067 \mu^{2}+0.0661 \mu- \\
0.0973\end{array}$ & $-0.0068 \mu^{2}+0.0686 \mu-0.0949$ \\
\hline$T_{1}(\mathrm{~s})$ & $0.376 \mu^{-0.261}$ & $0.396 \mu^{-0.292}$ \\
\hline C & $\begin{array}{c}0.0032 \mu^{2}-0.0303 \mu+ \\
0.531\end{array}$ & $0.0083 \mu^{2}-0.0723 \mu+0.683$ \\
\hline$T_{2}(\mathrm{~s})$ & $0.0654 \mu^{2}-0.637 \mu+2.409$ & $0.0559 \mu^{2}-0.569 \mu+2.39$ \\
\hline$k$ & $0.0316 \mu^{2}-0.282 \mu+1.051$ & $0.0454 \mu^{2}-0.395 \mu+1.363$ \\
\hline$n$ & $\begin{array}{c}-0.0205 \mu^{2}+0.183 \mu- \\
0.931\end{array}$ & $-0.0275 \mu^{2}+0.234 \mu-0.999$ \\
\hline
\end{tabular}

(4) The input energy spectra developed for ductility level $\mu=5$ can be used to estimate input energy for structures with ductility level $\mu>5$ with only a relative small margin of error. The last conclusion can easily be verified by plotting the proposed input energy spectra using (13) with values of the variables $a, b, C, k, n, T_{1}$, and $T_{2}$ obtained from Tables 6-9.

\section{Comparative Study of the Proposed Input Energy Spectra}

The proposed energy spectra are compared with response spectra generated using nonlinear time history analysis for three widely used major ground motion records given in Table 10. Earthquake records from the same events were selected for each soil category to facilitate the comparison of the relative performance of the proposed spectra among the different soil site types. Because the proposed energy spectra were developed based on a statistical measure mean $+\sigma$ and mean $+2 \sigma$ of a set of ground motion records normalized by the velocity index, VI, the proposed spectra will be compared with the mean $+\sigma$ and mean $+2 \sigma$ spectra obtained using time history analysis of the selected earthquakes for each soil site class. It is important to note that the relatively less number of earthquakes selected might give a very high standard deviation which in turn could result in higher design spectra value. However, this statistical magnification can be minimized through proper scaling of the ground motion records, which is a necessary element in any nonlinear dynamic analysis that involves a relatively small sample of ground motion records. The selected sets of earthquake records for each site were therefore scaled in accordance 
TABLE 8: Normalized input energy spectral shape parameters (site class D).

\begin{tabular}{|c|c|c|}
\hline & Mean $+\sigma$ & Mean $+2 \sigma$ \\
\hline \multicolumn{3}{|c|}{ Hysteresis model BP } \\
\hline$a$ & $-0.0011 \mu+1.03$ & $-0.0168 \mu+1.203$ \\
\hline$b$ & $0.0056 \mu-0.0151$ & $0.0069 \mu-0.0029$ \\
\hline$T_{1}(\mathrm{~s})$ & $0.571 \mu^{-0.206}$ & $0.594 \mu^{-0.224}$ \\
\hline C & $0.008 \mu^{2}-0.0831 \mu+0.647$ & $0.0122 \mu^{2}-0.124 \mu+0.815$ \\
\hline$T_{2}(\mathrm{~s})$ & $0.0142 \mu^{2}-0.119 \mu+2.282$ & $0.0151 \mu^{2}-0.123 \mu+2.286$ \\
\hline$k$ & $0.0118 \mu^{2}-0.116 \mu+0.905$ & $0.0128 \mu^{2}-0.137 \mu+1.038$ \\
\hline$n$ & $\begin{array}{c}-0.001 \mu^{2}-0.0174 \mu- \\
0.404\end{array}$ & $0.0067 \mu^{2}-0.062 \mu-0.284$ \\
\hline \multicolumn{3}{|c|}{ Hysteresis model SD } \\
\hline$a$ & $-0.0053 \mu+1.053$ & $-0.0351 \mu+1.237$ \\
\hline$b$ & $0.0167 \mu-0.0235$ & $0.021 \mu-0.0136$ \\
\hline$T_{1}(\mathrm{~s})$ & $0.553 \mu^{-0.245}$ & $0.571 \mu^{-0.241}$ \\
\hline C & $\begin{array}{c}0.0117 \mu^{2}-0.0991 \mu+ \\
0.654\end{array}$ & $0.0179 \mu^{2}-0.151 \mu+0.828$ \\
\hline$T_{2}(\mathrm{~s})$ & $\begin{array}{c}-0.0119 \mu^{2}-0.0156 \mu+ \\
2.388\end{array}$ & $-0.0101 \mu^{2}-0.0276 \mu+2.428$ \\
\hline$k$ & $\begin{array}{c}-0.0017 \mu^{2}-0.0148 \mu+ \\
0.873\end{array}$ & $0.004 \mu^{2}-0.0581 \mu+1.016$ \\
\hline$n$ & $0.0222 \mu^{2}-0.2 \mu-0.303$ & $0.0235 \mu^{2}-0.213 \mu-0.182$ \\
\hline \multicolumn{3}{|c|}{ Hysteresis model BF } \\
\hline$a$ & $0.0204 \mu+1.029$ & $-0.0117 \mu^{2}+0.0793 \mu+1.123$ \\
\hline$b$ & $0.0038 \mu-0.0153$ & $0.0018 \mu^{2}-0.0057 \mu+0.009$ \\
\hline$T_{1}(\mathrm{~s})$ & $0.561 \mu^{-0.223}$ & $0.579 \mu^{-0.235}$ \\
\hline C & $\begin{array}{c}0.0097 \mu^{2}-0.0879 \mu+ \\
0.649\end{array}$ & $0.0156 \mu^{2}-0.136 \mu+0.822$ \\
\hline$T_{2}(\mathrm{~s})$ & $0.0171 \mu^{2}-0.267 \mu+3.134$ & $-0.017 \mu^{2}+0.0096 \mu+2.758$ \\
\hline$k$ & $0.0277 \mu^{2}-0.251 \mu+1.423$ & $0.0299 \mu^{2}-0.202 \mu+1.343$ \\
\hline$n$ & $\begin{array}{c}-0.0058 \mu^{2}+0.0093 \mu- \\
0.708\end{array}$ & $-0.0111 \mu^{2}-0.0114 \mu-0.484$ \\
\hline \multicolumn{3}{|c|}{ Hysteresis model BS } \\
\hline$a$ & $0.0878 \mu+0.986$ & $0.0811 \mu+1.142$ \\
\hline$b$ & $0.0122 \mu-0.0153$ & $0.0139 \mu-0.0019$ \\
\hline$T_{1}(\mathrm{~s})$ & $0.561 \mu^{-0.352}$ & $0.587 \mu^{-0.349}$ \\
\hline C & $0.005 \mu^{2}-0.0498 \mu+0.615$ & $0.0073 \mu^{2}-0.0747 \mu+0.766$ \\
\hline$T_{2}(\mathrm{~s})$ & $0.0731 \mu^{2}-0.687 \mu+3.454$ & $0.0428 \mu^{2}-0.450 \mu+3.145$ \\
\hline$k$ & $0.0251 \mu^{2}-0.242 \mu+1.403$ & $-0.0086 \mu^{2}+0.0008 \mu+1.196$ \\
\hline$n$ & $\begin{array}{c}0.0043 \mu^{2}-0.0618 \mu- \\
0.645\end{array}$ & $0.0278 \mu^{2}-0.238 \mu-0.316$ \\
\hline
\end{tabular}

with the procedures outlined in FEMA P695 [52] and PEER ground motion database technical manual [53]. The ground motion indices and scaling factors used in the analysis are summarized in Table 11. The comparisons for the four soil site classes and hysteresis models are shown in Figures 69. As can be seen, the proposed energy mean $+\sigma$ and mean $+2 \sigma$ spectra generally produce spectral values that are conservative for a large range of periods.

\section{Proposed Hysteretic Energy Spectra}

As indicated earlier, only a portion of the input energy that is imparted to a structure during a seismic event will cause damage to the structure. Of the three forms of energy shown on the left side of (3), the one that is likely to cause the most damage is a part of the absorbed energy, namely, hysteretic energy, HE. A designer using an energy-based seismic design method is required to estimate this hysteretic energy and design the structure so it is capable of dissipating this destructive energy. Through statistical analysis it is possible to develop hysteretic energy spectra. However, because the damage index or intensity of earthquakes has little or no direct relationship with hysteretic energy or hysteretic behavior of structural systems, it might be unrealistic to develop hysteretic energy spectra that can be scaled to a desired intensity of design earthquake. Furthermore, Manfredi (2001) and Ye et al. [54] reported that input energy is a stable parameter for assessing structural response. Mollaioli et al. [55] 
TABLE 9: Normalized input energy spectral shape parameters (site class E).

\begin{tabular}{|c|c|c|}
\hline & Mean $+\sigma$ & Mean $+2 \sigma$ \\
\hline \multicolumn{3}{|c|}{ Hysteresis model BP } \\
\hline$a$ & $0.0118 \mu+0.84$ & $-0.0057 \mu+1.068$ \\
\hline$b$ & $0.0048 \mu-0.0092$ & $0.0072 \mu+0.0037$ \\
\hline$T_{1}(\mathrm{~s})$ & $0.823 \mu^{-0.257}$ & $0.818 \mu^{-0.265}$ \\
\hline C & $0.0157 \mu^{2}-0.140 \mu+0.821$ & $0.0237 \mu^{2}-0.211 \mu+1.073$ \\
\hline$T_{2}(\mathrm{~s})$ & $3.338 \mu^{-0.194}$ & $3.413 \mu^{-0.218}$ \\
\hline$k$ & $0.305 \mu^{2}-2.495 \mu+6.033$ & $0.538 \mu^{2}-4.308 \mu+9.536$ \\
\hline$n$ & $-0.0609 \mu^{2}+0.517 \mu-1.908$ & $-0.0738 \mu^{2}+0.626 \mu-2.107$ \\
\hline \multicolumn{3}{|c|}{ Hysteresis model SD } \\
\hline$a$ & $0.0456 \mu+0.803$ & $-0.0053 \mu^{2}+0.0493 \mu+1.009$ \\
\hline$b$ & $0.0098 \mu-0.0108$ & $0.0144 \mu$ \\
\hline$T_{1}(\mathrm{~s})$ & $0.833 \mu-0.348$ & $0.815 \mu^{-0.33}$ \\
\hline$C$ & $0.0181 \mu^{2}-0.148 \mu+0.828$ & $0.0284 \mu^{2}-0.231 \mu+1.085$ \\
\hline$T_{2}(\mathrm{~s})$ & $3.293 \mu^{-0.289}$ & $3.336 \mu^{-0.286}$ \\
\hline$k$ & $0.344 \mu^{2}-2.699 \mu+6.116$ & $0.621 \mu^{2}-4.715 \mu+9.721$ \\
\hline$n$ & $-0.069 \mu^{2}+0.528 \mu-1.881$ & $-0.101 \mu^{2}+0.726 \mu-2.139$ \\
\hline \multicolumn{3}{|c|}{ Hysteresis model BF } \\
\hline$a$ & $0.0154 \mu+0.821$ & $-0.0047 \mu+1.047$ \\
\hline$b$ & $0.0044 \mu-0.008$ & $0.0075 \mu+0.0044$ \\
\hline$T_{1}(\mathrm{~s})$ & $0.854 \mu^{-0.22}$ & $0.85 \mu^{-0.219}$ \\
\hline C & $0.0115 \mu^{2}-0.107 \mu+0.801$ & $0.0187 \mu^{2}-0.17 \mu+1.048$ \\
\hline$T_{2}(\mathrm{~s})$ & $33.308 \mu^{-0.262}$ & $3.354 \mu^{-0.266}$ \\
\hline$k$ & $0.283 \mu^{2}-2.32 \mu+5.848$ & $0.533 \mu^{2}-4.181 \mu+9.34$ \\
\hline$n$ & $-0.0487 \mu^{2}+0.395 \mu-1.774$ & $-0.0716 \mu^{2}+0.544 \mu-1.992$ \\
\hline \multicolumn{3}{|c|}{ Hysteresis model BS } \\
\hline$a$ & $0.123 \mu+0.749$ & $0.117 \mu+0.932$ \\
\hline$b$ & $0.006 \mu+0.0005$ & $0.0092 \mu+0.0202$ \\
\hline$T_{1}(\mathrm{~s})$ & $0.822 \mu^{-0.449}$ & $0.824 \mu^{-0.434}$ \\
\hline C & $0.0125 \mu^{2}-0.105 \mu+0.787$ & $0.0224 \mu^{2}-0.180 \mu+1.039$ \\
\hline$T_{2}(\mathrm{~s})$ & $3.292 \mu^{-0.39}$ & $3.368 \mu^{-0.356}$ \\
\hline$k$ & $0.365 \mu^{2}-2.818 \mu+6.167$ & $0.615 \mu^{2}-4.647 \mu+9.625$ \\
\hline$n$ & $-0.0859 \mu^{2}+0.603 \mu-1.914$ & $-0.106 \mu^{2}+0.722 \mu-2.108$ \\
\hline
\end{tabular}

TABLE 10: Earthquake records used in the comparative study.

\begin{tabular}{|c|c|c|c|c|c|}
\hline Soil type & Ground motion & Year & Magnitude & $V_{s 30}(\mathrm{~m} / \mathrm{s})$ & Station \\
\hline \multirow{3}{*}{ B } & Loma Prieta, & 1989 & 6.93 & 1249.9 & SF-Pacific Height \\
\hline & Northridge-01 & 1994 & 6.69 & 821.7 & Anacapa Island \\
\hline & Chi-Chi Taiwan & 1999 & 7.62 & 999.7 & TCU085 \\
\hline \multirow{3}{*}{$\mathrm{C}$} & Loma Prieta & 1989 & 6.93 & 367.6 & Fremont-Mission \\
\hline & Northridge-01 & 1994 & 6.69 & 684.9 & Leona Valley \#1 \\
\hline & Chi-Chi Taiwan & 1999 & 6.2 & 442.1 & CHY 046 \\
\hline \multirow{3}{*}{$\mathrm{D}$} & Loma Prieta & 1989 & 6.93 & 271.1 & Dublin-Fire Station \\
\hline & Northridge-01 & 1994 & 6.69 & 234.9 & Camarillo \\
\hline & Chi-Chi Taiwan & 1999 & 6.3 & 271.1 & CHY037 \\
\hline \multirow{3}{*}{$\mathrm{E}$} & Loma Prieta & 1989 & 6.93 & 155.1 & Treasure \\
\hline & Northridge-01 & 1994 & 6.69 & 160.6 & Carson \\
\hline & Chi-Chi Taiwan 04 & 1999 & 6.2 & 172.1 & CHY054 \\
\hline
\end{tabular}



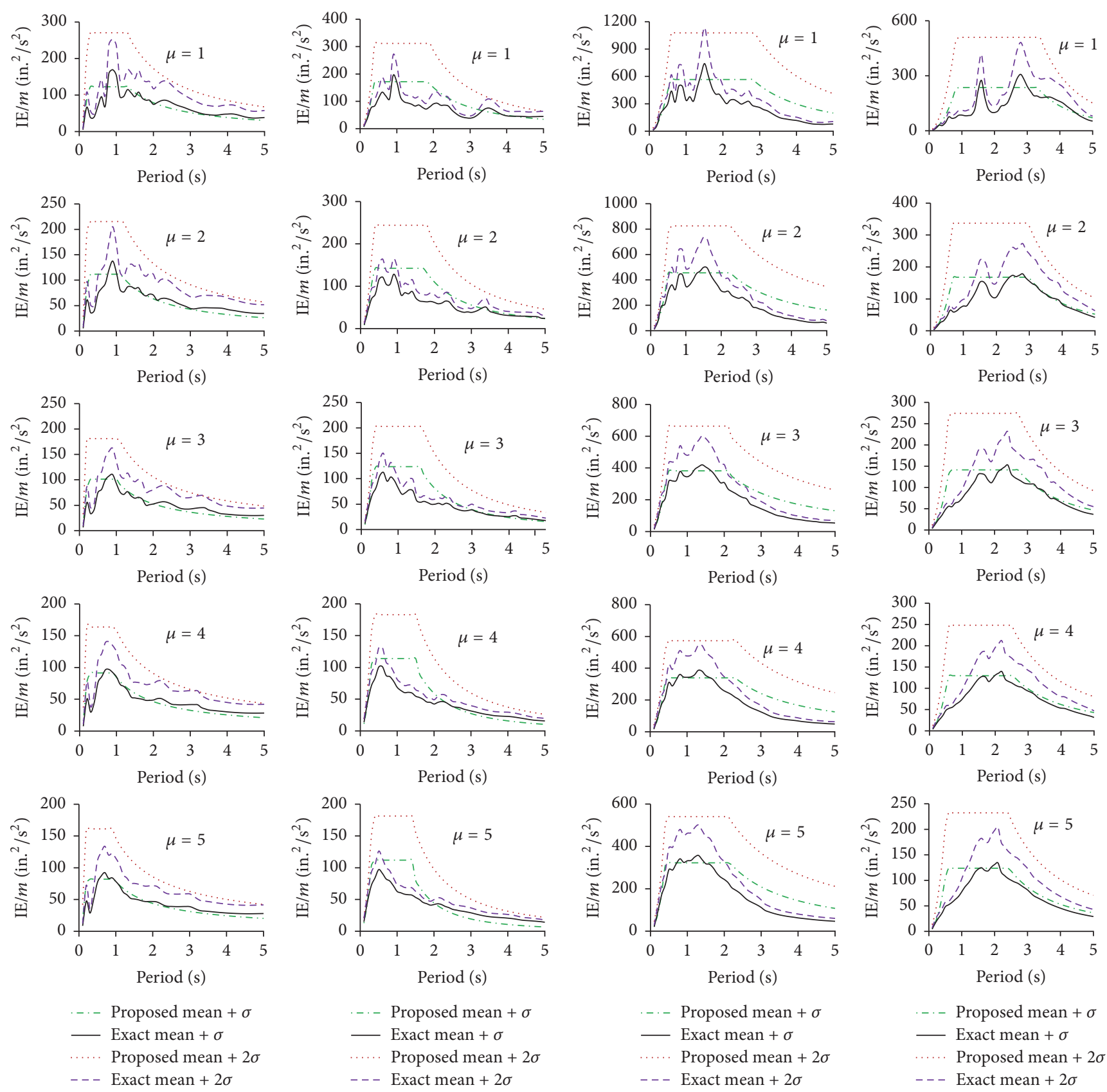

(a) Soil site B

(b) Soil site C

(c) Soil site $\mathrm{D}$

(d) Soil site E

FIGURE 6: Comparative study of proposed input energy spectra: hysteresis model $\mathrm{BP}(\zeta=5 \%, \alpha=0.05)$.

also observed that most stable seismic parameters could be obtained by setting a relationship between the square root of input energy and displacement (which is dependent on hysteretic behavior) and asserted that input energy could effectively be used to represent seismic demand in structural systems. Therefore, instead of developing explicit hysteretic energy spectra, spectra that relate hysteretic energy (HE) to input energy (IE), that is, hysteretic energy to input energy ratio (HE/IE), will be proposed in this study.

In developing the (HE/IE) spectra, the same suites of earthquake records used for developing the proposed normalized input energy spectra were used. For each soil site class, hysteretic behavior dependent mean $+\sigma$ and mean + $2 \sigma \mathrm{HE} / \mathrm{IE}$ spectra are proposed. The spectra were developed from the energy ratios of time history analysis results of scaled earthquakes selected for a given site class. The steps for carrying out the analysis are given below.

Step 1. For a given hysteresis model and ductility value, the input energy spectral values are obtained from a nonlinear analysis using BISPEC (2012) for the selected set of earthquakes for the given soil site class, and the corresponding 

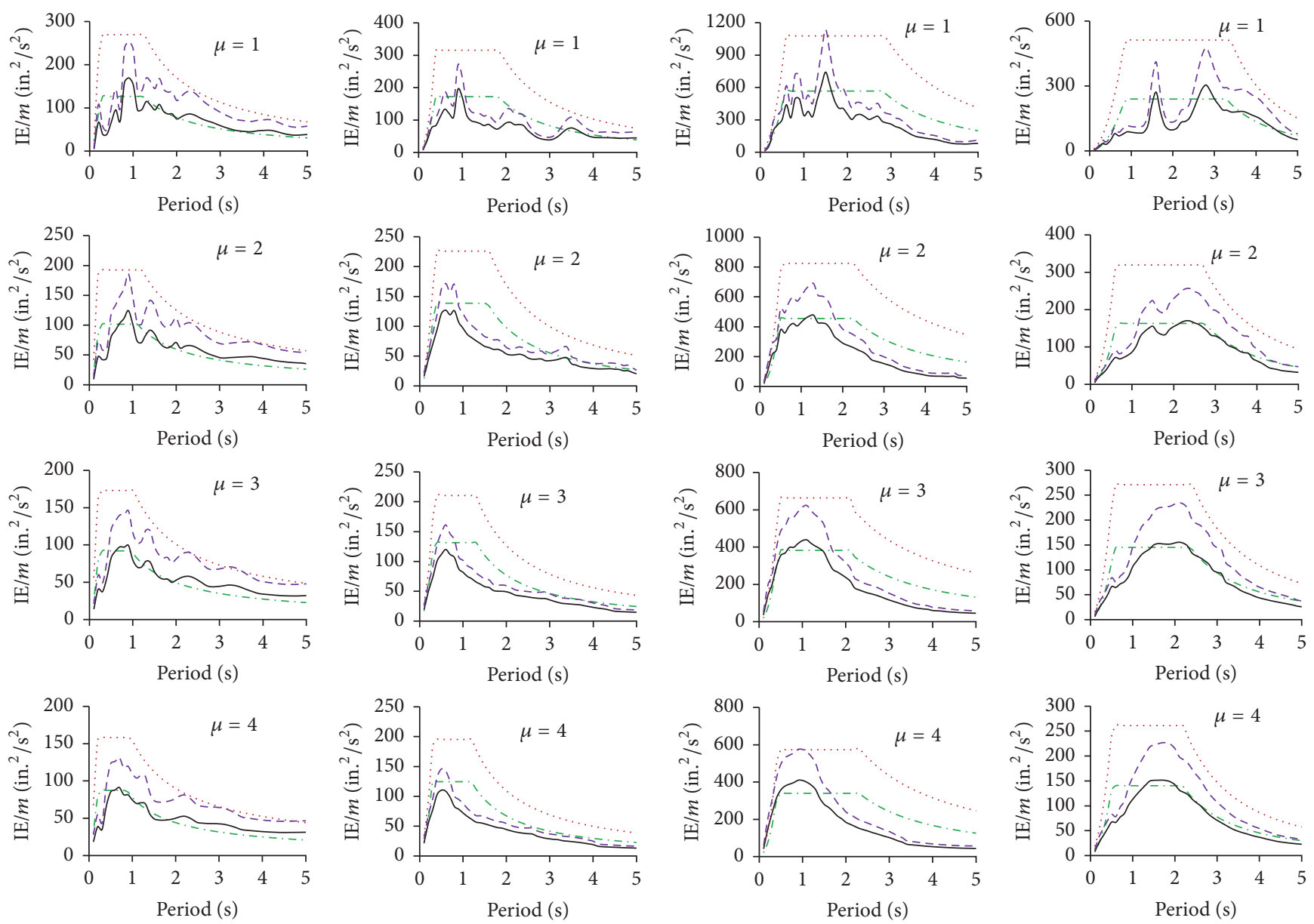

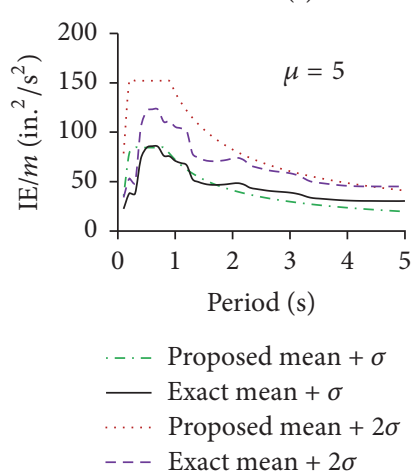

(a) Soil site $B$

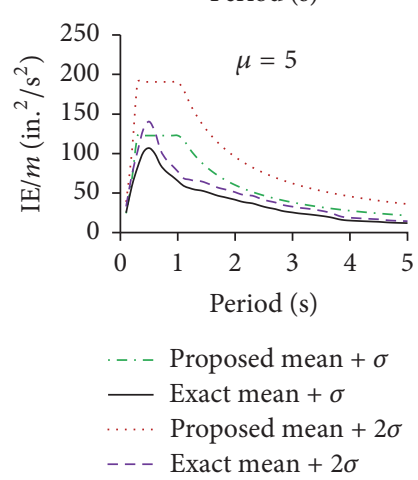

(b) Soil site C

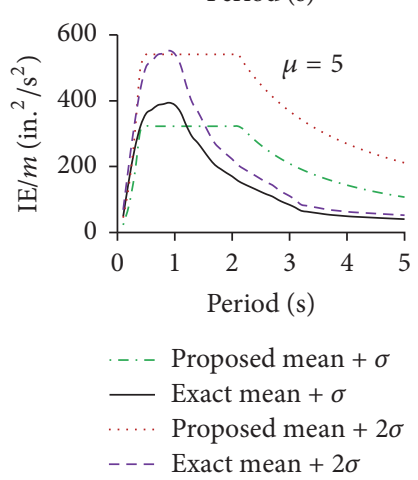

(c) Soil site D

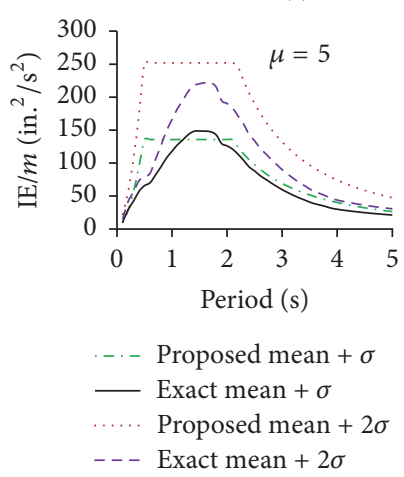

(d) Soil site E

FIGURE 7: Comparative study of proposed input energy spectra: hysteresis model $\operatorname{SD}(\zeta=5 \%, \alpha=0.05)$.

mean $+\sigma$ and mean $+2 \sigma$ of input energy spectral values are calculated.

Step 2. Similarly, using the same set of earthquakes, the mean $+\sigma$ and mean $+2 \sigma$ hysteretic energy spectral values for the given hysteresis model and ductility value are calculated using the hysteretic energy spectral values obtained from BISPEC.

Step 3. Hysteretic energy to input energy ratios, HE/IE, are then obtained as follows:

$$
\begin{gathered}
\frac{\mathrm{HE}}{\mathrm{IE}}(\text { mean }+\sigma)=\frac{\mathrm{HE}(\text { mean }+\sigma)}{\mathrm{IE}(\text { mean }+\sigma)}, \\
\frac{\mathrm{HE}}{\mathrm{IE}}(\text { mean }+2 \sigma)=\frac{\mathrm{HE}(\text { mean }+2 \sigma)}{\mathrm{IE}(\text { mean }+2 \sigma)} .
\end{gathered}
$$

Step 4. The values obtained in Step 3 are then used to generate HE/IE spectra.

Figure 10 shows some sample HE/IE spectra for soil site class B. Spectra for soil site classes C, D, and E were found 

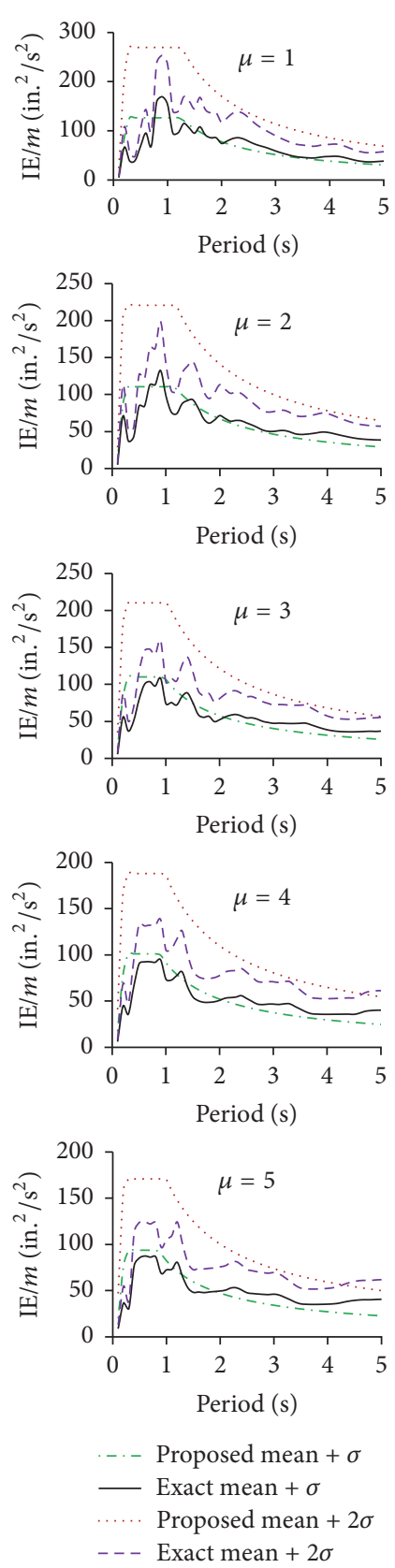

(a) Soil site B
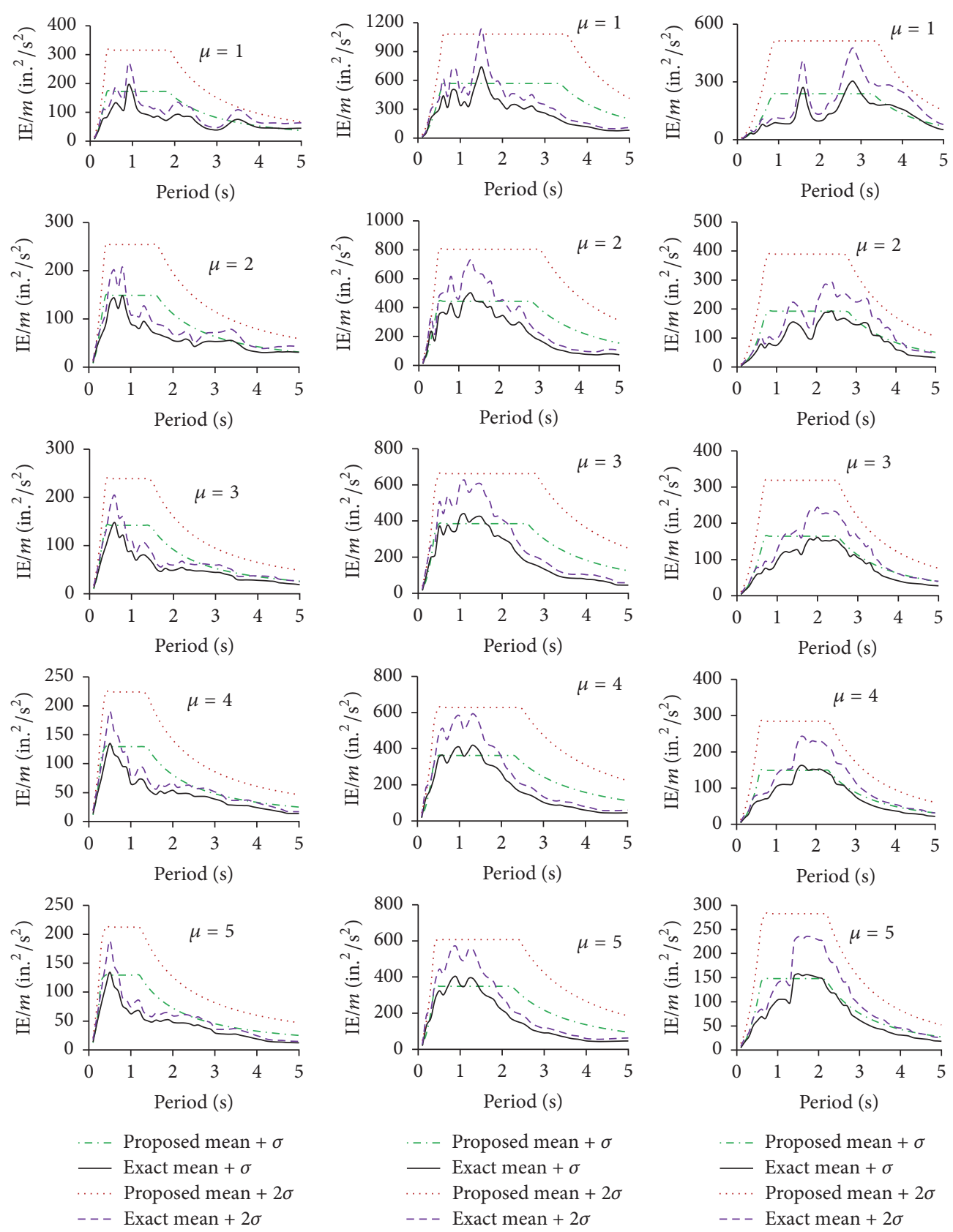

(b) Soil site $\mathrm{C}$

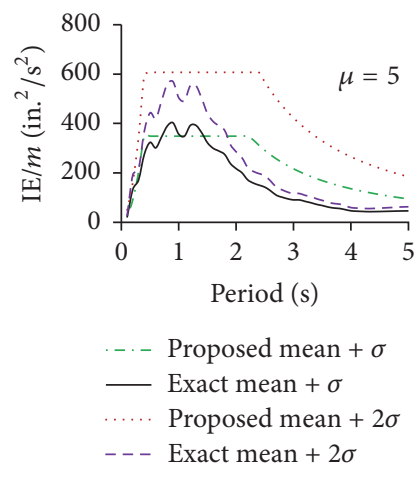

(c) Soil site D

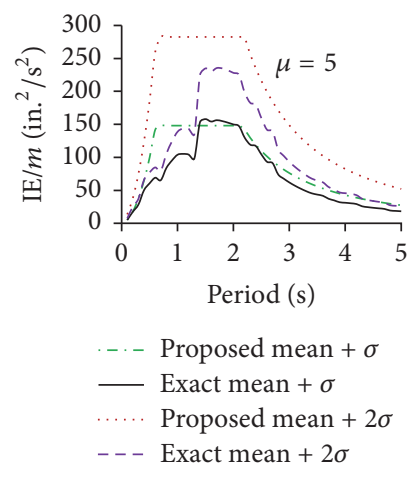

(d) Soil site E

FIGURE 8: Comparative study of proposed input energy spectra: hysteresis model $\mathrm{BF}(\zeta=5 \%, \alpha=0.05)$.

to have similar spectral shapes. In other words, for a given hysteresis model, the mean $+\sigma$ and mean $+2 \sigma \mathrm{HE} / \mathrm{IE}$ spectra exhibited similar variations in spectral values with period. This is true, irrespective of the soil site characteristics and for ductility levels $\mu=2,3,4$, and 5 considered in this study. However, as can be seen from Figure 10, the HE/IE spectral shapes do not show similar characteristics among the different hysteresis models considered in this study. As a result, the following hysteresis model dependent general shapes have been adopted in developing smoothened HE/IE spectra.
8.1. Hysteresis Model BP. Spectral values at the extreme left end of the short period region increase with period (albeit, for a very small period range) until the maximum value is reached (see Figure 10(a)). For instance, the periods that correspond to these maximum values are $0.28,0.28,0.32$, and 0.35 s for ductility levels of $\mu=2,3,4$, and 5 , respectively. These values are well below the periods of vibrations for most civil engineering structures. Moreover, the spectral values in the short period region are not significantly lower than the maximum value. As a result, the maximum value in the intermediate regions was assumed to extend into the 

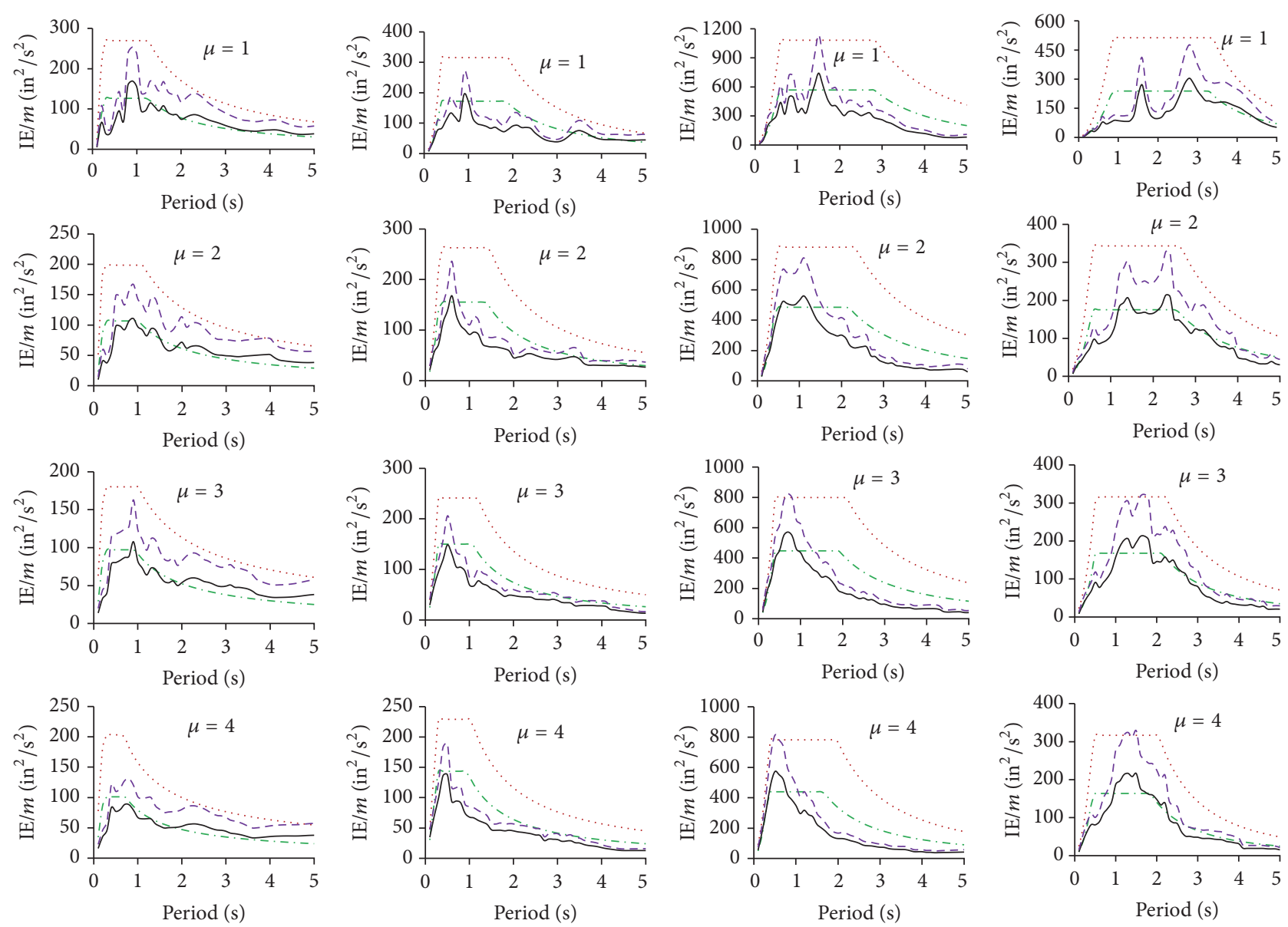

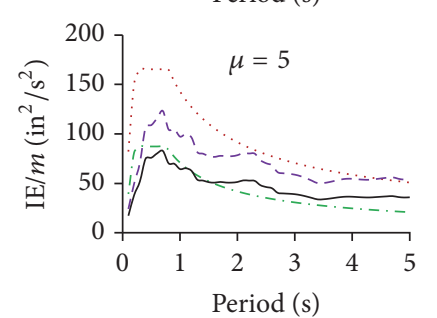

- - Proposed mean $+\sigma$

- Exact mean $+\sigma$

.... Proposed mean $+2 \sigma$

- - Exact mean $+2 \sigma$

(a) Soil site B

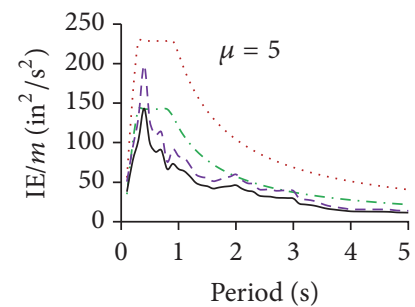

Proposed mean $+\sigma$

_ Exact mean $+\sigma$

..... Proposed mean $+2 \sigma$

- - Exact mean $+2 \sigma$

(b) Soil site C

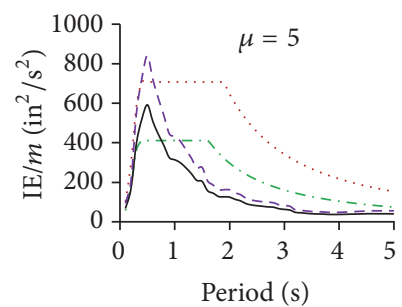

-. Proposed mean $+\sigma$

- Exact mean $+\sigma$

.... Proposed mean $+2 \sigma$

- - - Exact mean $+2 \sigma$

(c) Soil site D

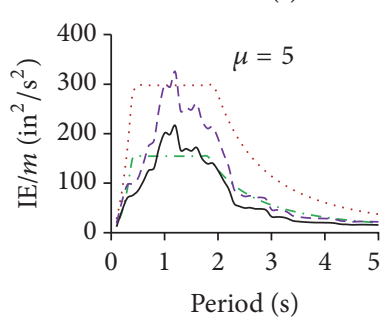

-. Proposed mean $+\sigma$

- Exact mean $+\sigma$

..... Proposed mean $+2 \sigma$

-- Exact mean $+2 \sigma$

(d) Soil site E

FIGURE 9: Comparative study of proposed input energy spectra: hysteretic model BS $(\zeta=5 \%, \alpha=0.05)$.

short period region. In the long period region the spectral values do not exponentially decrease and thus the values were considered to vary linearly. Accordingly, the smoothened spectra were considered to have the general shape shown in Figure 11.

8.2. Hysteresis Models SD and BF. For these hysteresis models (shown in Figures 10(b) and 10(c)), the HE/IE spectral values in the short period do not strictly increase or decrease with period. However, for simplicity, the general HE/IE spectral shape shown in Figure 11 is adopted for hysteresis models SD and $\mathrm{BF}$.
8.3. Hysteresis Model BS. The HE/IE spectra for hysteresis model BS (shown in Figure $10(\mathrm{~d})$ ) show a significant difference between the smallest value of the short period region and the maximum value of the intermediate region. Therefore, instead of extending the shape of the spectra in the intermediate region spectra into the short period region, a trilinear shape as shown in Figure 12 is proposed.

Using the steps above and the specific spectral shapes adopted, hysteretic behavior dependent HE/IE spectra taking into consideration the effect of ductility were developed for soil site classes B, C, D, and E. The spectral shape parameters that define the proposed mean $+\sigma$ and mean $+2 \sigma \mathrm{HE} / \mathrm{IE}$ 

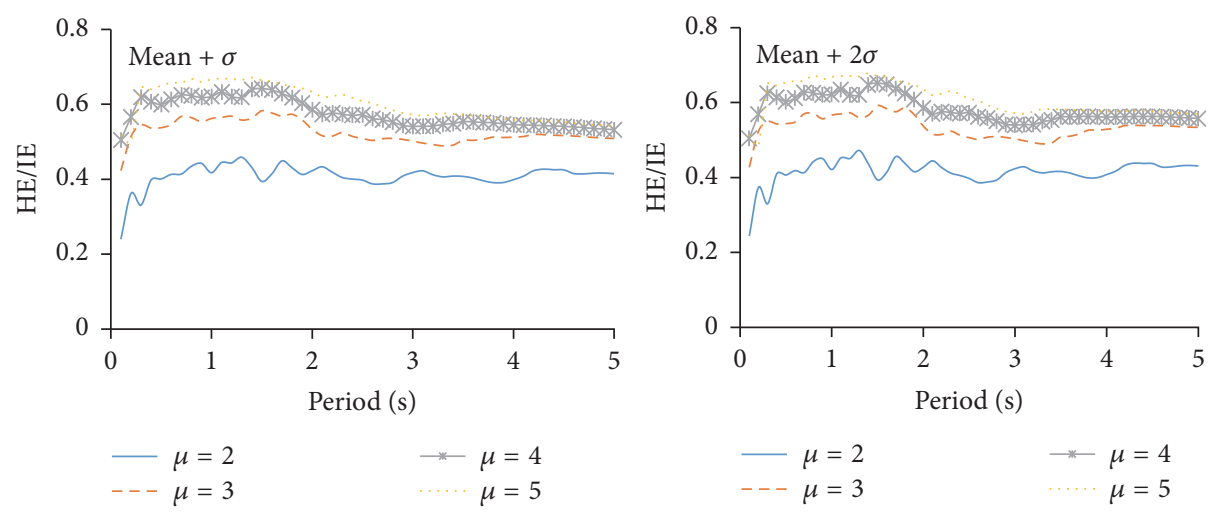

(a) Bilinear plastic
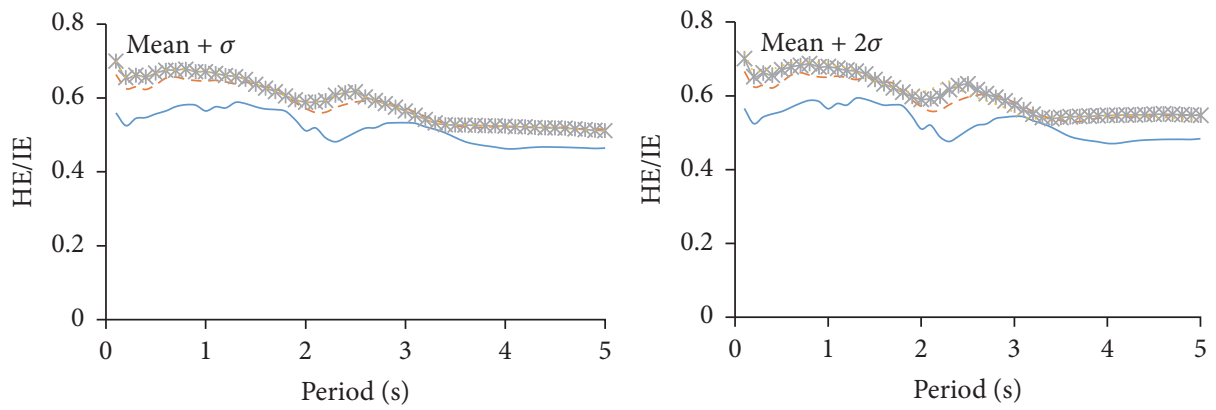

$$
-\mu=2
$$$$
\because \mu=4
$$$$
\text { - } \mu=4
$$

$\mu=5$

$$
\begin{array}{r}
-\mu=2 \\
--\mu=3
\end{array}
$$$$
\mu=5
$$

(b) Stiffness degradation
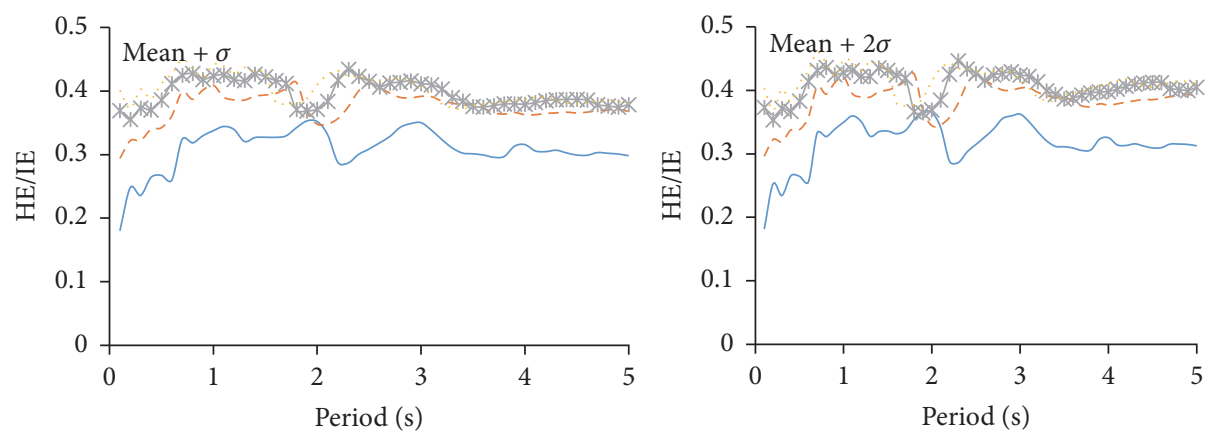

$$
-\mu=2
$$$$
\rightarrow \mu=4
$$

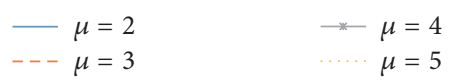

(c) Bilinear flag
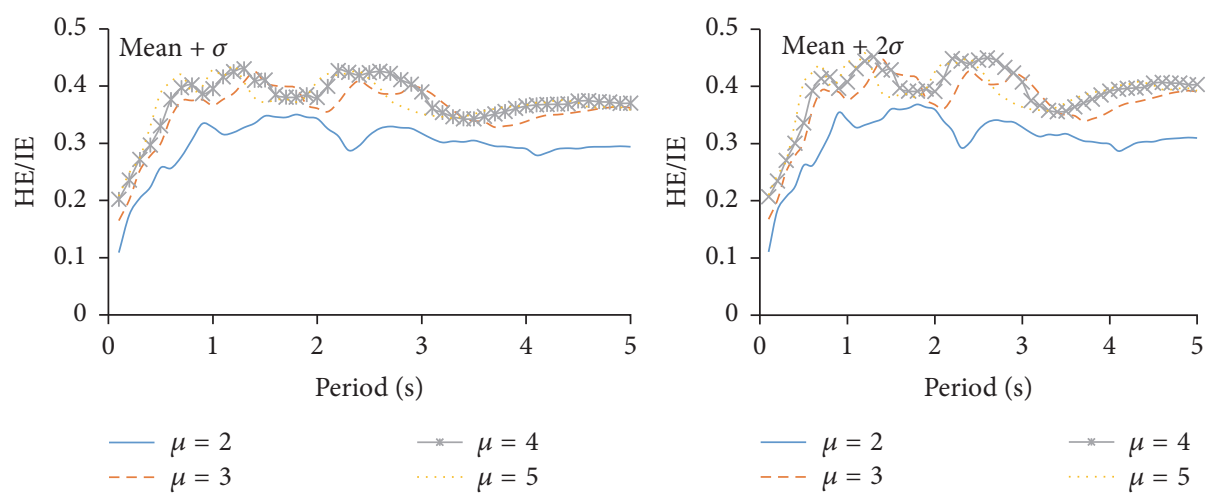

(d) Bilinear slip

FIgURE 10: HE/IE spectra for soil site class B. 
TABLE 11: Ground motion indices and scaling factor.

\begin{tabular}{|c|c|c|c|c|c|c|c|c|}
\hline \multirow{2}{*}{ Soil type } & \multirow{2}{*}{ Ground motion } & \multicolumn{3}{|c|}{ Fault normal component } & \multicolumn{3}{|c|}{ Fault parallel component } & \multirow{2}{*}{ Scale factor } \\
\hline & & CAV & PGA & PGV & CAV & PGA & PGV & \\
\hline \multirow{3}{*}{ B } & Loma Prieta & 1.851 & 0.628 & 0.150 & 1.355 & 0.388 & 0.060 & 1.149 \\
\hline & Northridge-01 & 2.307 & 0.640 & 0.0316 & 1.724 & 0.357 & 0.0199 & 1.634 \\
\hline & Chi-Chi Taiwan & 3.103 & 0.695 & 0.0751 & 2.73 & 0.507 & 0.073 & 1.205 \\
\hline \multirow{3}{*}{$\mathrm{C}$} & Loma Prieta & 4.666 & 1.416 & 0.0949 & 5.415 & 1.335 & 0.136 & 0.809 \\
\hline & Northridge-01 & 2.728 & 1.060 & 0.079 & 1.868 & 0.449 & 0.0634 & 1.407 \\
\hline & Chi-Chi Taiwan & 4.112 & 1.160 & 0.090 & 4.120 & 1.013 & 0.088 & 0.92 \\
\hline \multirow{3}{*}{$\mathrm{D}$} & Loma Prieta & 3.657 & 0.715 & 0.0732 & 3.116 & 0.736 & 0.0471 & 1.679 \\
\hline & Northridge-01 & 8.780 & 1.146 & 0.131 & 8.714 & 0.958 & 4.3114 & 1.03 \\
\hline & Chi-Chi Taiwan & 5.971 & 1.159 & 0.127 & 7.035 & 1.534 & 0.110 & 0.899 \\
\hline \multirow{3}{*}{$\mathrm{E}$} & Loma Prieta & 3.464 & 1.259 & 0.272 & 3.243 & 1.484 & 0.230 & 0.383 \\
\hline & Northridge-01 & 4.812 & 0.747 & 0.0727 & 5.023 & 0.966 & 0.0698 & 0.691 \\
\hline & Chi-Chi Taiwan & 4.091 & 0.431 & 0.084 & 3.821 & 0.493 & 0.0679 & 1.046 \\
\hline
\end{tabular}

Units for CAV and PGV are $\mathrm{m} / \mathrm{s}$ and that for PGA is $\mathrm{m} / \mathrm{s}^{2}$.

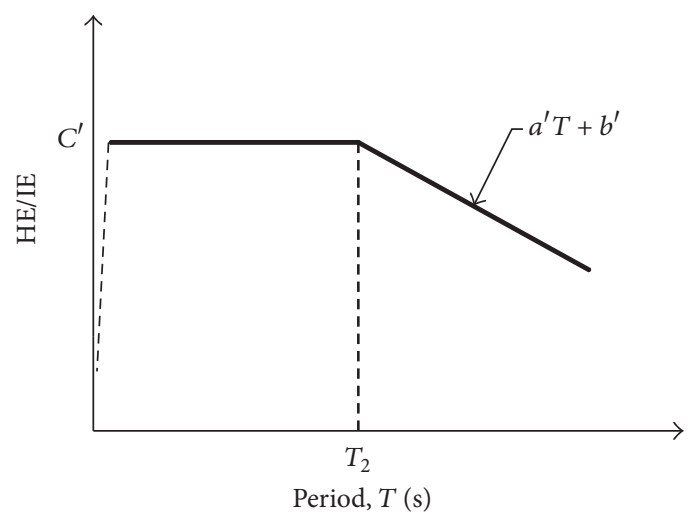

FIgURE 11: Proposed HE/IE spectra for hysteresis models BP, SD, and BF.

spectra for the four soil site classes at ductility levels $\mu=$ $2,3,4,5$ are given in Tables $12-15$. Note that when $\mu=1$, the system remains elastic and so the hysteretic energy will be zero. Also, for natural period that exceeds 5 , the spectral shape constants are not given as $T>5$ is beyond the scope of the present study.

Some general trends of the proposed HE/IE spectra can be summarized as follows. (1) The soil site effect on the $\mathrm{HE} / \mathrm{IE}$ spectra varies from one hysteresis model to another. For systems with BP hysteretic behavior, the HE/IE spectral values exhibit slight increase as the soil gets softer whereas systems with BS hysteretic behavior show just the opposite. For systems that show SD and BF hysteretic behavior, the $\mathrm{HE} / \mathrm{IE}$ spectral values in the short and intermediate regions increase slightly as the soil gets softer, whereas the effect in the long period region is mixed. However, because soil site effect on the HE/IE spectral values seems rather negligible, it can be ignored. The same conclusion was reached by Ye et al. (2009) and López-Almansa et al. (2013). (2) For soil site classes $\mathrm{C}, \mathrm{D}$, and $\mathrm{E}$, hysteretic behavior tends to affect the $\mathrm{HE} / \mathrm{IE}$ spectral values in the following order: $\mathrm{BP}>\mathrm{SD}>$
$\mathrm{BF}>\mathrm{BS}$. For site class $\mathrm{B}$, the same trend was observed in the short period region whereas in the long and intermediate regions the HE/IE spectral values for hysteresis model BS were more noticeable than those for BF. (3) The HE/IE spectral values increase with ductility level. The difference in $\mathrm{HE} / \mathrm{IE}$ spectral values between the different ductility levels is more pronounced at lower ductility levels but diminishes at higher ductility levels. This observation is in agreement with the findings reported by López-Almansa et al. (2013).

To obtain the mean $+\sigma$ or mean $+2 \sigma$ hysteretic energy spectra from the proposed HE/IE spectra, the mean $+\sigma$ or mean $+2 \sigma$ input energy per unit mass $(\mathrm{IE} / m)$ spectra are first obtained using (14). The proposed mean $+\sigma$ and mean $+2 \sigma$ hysteretic energy per unit mass spectra can then be obtained by multiplying the resulting mean $+\sigma$ and mean $+2 \sigma \mathrm{IE} / m$ spectra by the corresponding HE/IE spectral values. Figures 13-16 show plots of the proposed $\mathrm{HE} / m$ spectra (curves labelled proposed mean $+\sigma$ and proposed mean $+2 \sigma$ ) for the four hysteresis models (BP, SD, BF, and BS), four soil site classes (B, C, D, and E), and four ductility levels ( $\mu=$ $2,3,4,5)$. 


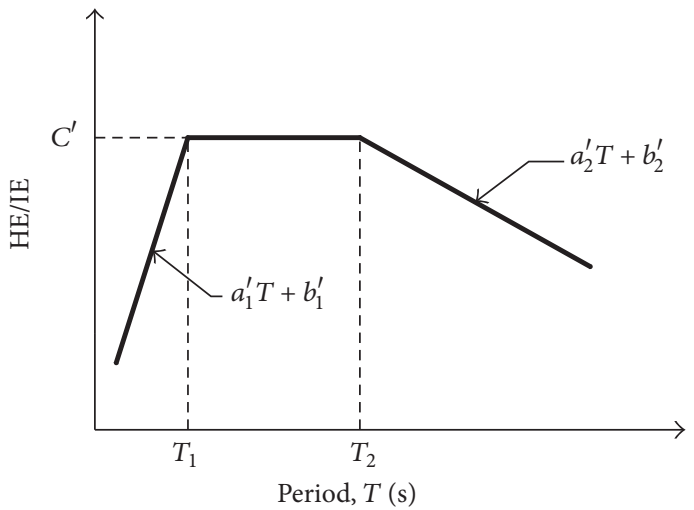

FIGURE 12: Proposed HE/IE spectra for hysteresis model BS.
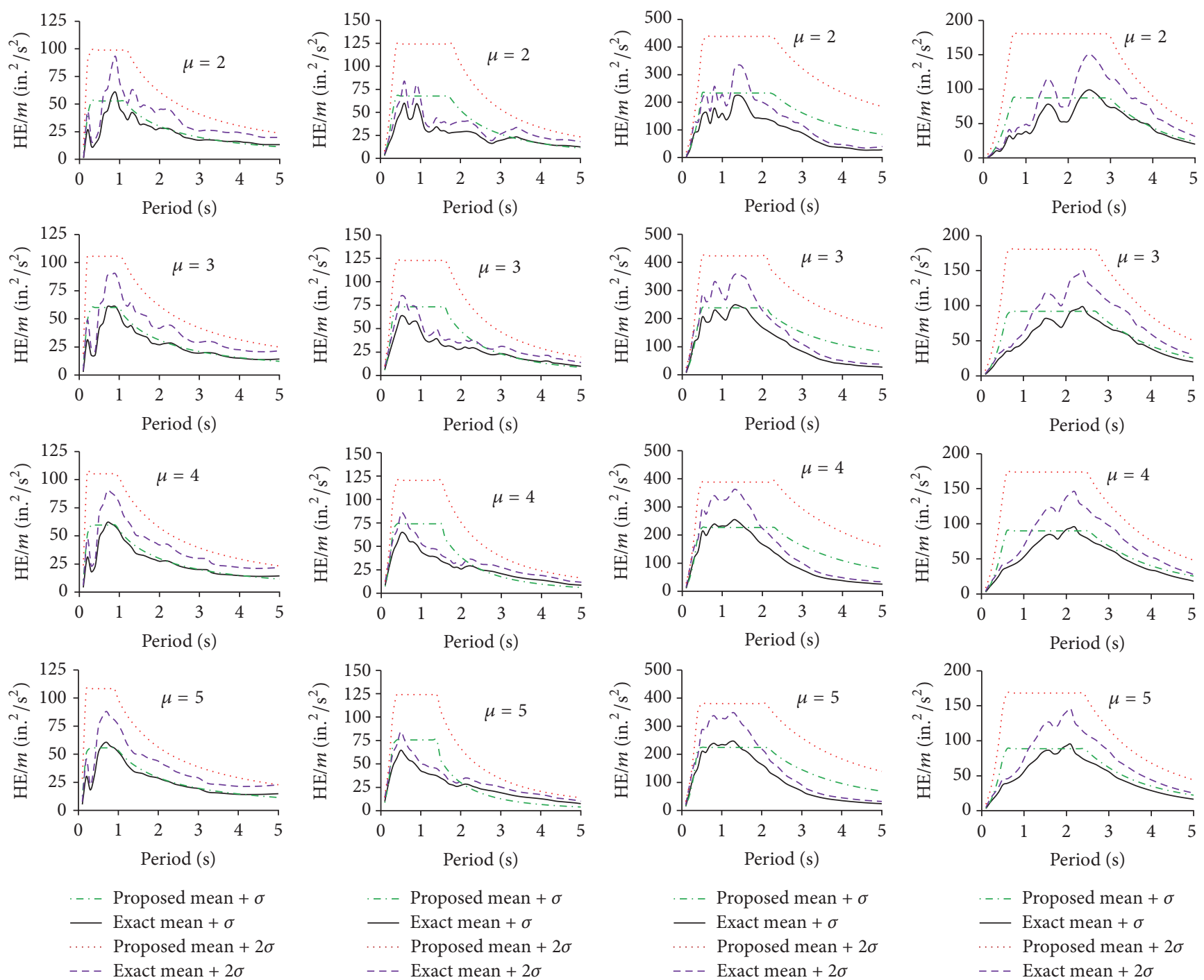

(a) Soil site B

(b) Soil site $\mathrm{C}$

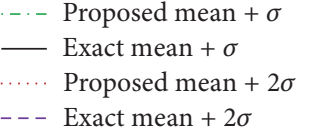

- Proposed mean $+\sigma$

Exact mean $+\sigma$

Proposed mean $+2 \sigma$

(c) Soil site D

(d) Soil site E

FIGURE 13: Comparative study of proposed hysteretic energy spectra: hysteresis model BP. 
TABLE 12: HE/IE spectral shape parameters for soil site class B.

\begin{tabular}{|c|c|c|c|c|c|c|c|c|}
\hline \multirow[b]{3}{*}{$\mu$} & \multicolumn{4}{|c|}{ Mean $+\sigma$} & \multicolumn{4}{|c|}{ Mean $+2 \sigma$} \\
\hline & \multicolumn{8}{|c|}{ Hysteresis model BP } \\
\hline & 2 & 3 & 4 & 5 & 2 & 3 & 4 & 5 \\
\hline$C^{\prime}$ & 0.459 & 0.583 & 0.642 & 0.671 & 0.472 & 0.592 & 0.652 & 0.678 \\
\hline$T_{2}(\mathrm{~s})$ & 2.275 & 2.008 & 1.727 & 1.573 & 2.372 & 2.108 & 1.805 & 1.599 \\
\hline$a^{\prime}$ & -0.0157 & -0.0233 & -0.0333 & -0.0383 & -0.0157 & -0.02 & -0.03 & -0.0333 \\
\hline \multirow[t]{2}{*}{$b^{\prime}$} & 0.495 & 0.63 & 0.7 & 0.732 & 0.51 & 0.634 & 0.706 & 0.732 \\
\hline & \multicolumn{8}{|c|}{ Hysteresis model SD } \\
\hline$\mu$ & 2 & 3 & 4 & 5 & 2 & 3 & 4 & 5 \\
\hline$C^{\prime}$ & 0.588 & 0.656 & 0.678 & 0.684 & 0.593 & 0.663 & 0.686 & 0.691 \\
\hline$T_{2}(\mathrm{~s})$ & 1.565 & 1.306 & 1.096 & 1.041 & 1.685 & 1.479 & 1.104 & 1.129 \\
\hline$a^{\prime}$ & -0.0362 & -0.0377 & -0.0423 & -0.0464 & -0.033 & -0.0348 & -0.0358 & -0.0404 \\
\hline \multirow[t]{2}{*}{$b^{\prime}$} & 0.645 & 0.706 & 0.725 & 0.732 & 0.649 & 0.714 & 0.726 & 0.737 \\
\hline & \multicolumn{8}{|c|}{ Hysteresis model BF } \\
\hline$\mu$ & 2 & 3 & 4 & 5 & 2 & 3 & 4 & 5 \\
\hline$C^{\prime}$ & 0.353 & 0.413 & 0.434 & 0.449 & 0.366 & 0.425 & 0.446 & 0.46 \\
\hline$T_{2}(\mathrm{~s})$ & 3.115 & 2.73 & 2.492 & 2.124 & 3.179 & 2.775 & 2.481 & 2.135 \\
\hline$a^{\prime}$ & -0.0291 & -0.02 & -0.022 & -0.0225 & -0.0291 & -0.015 & -0.016 & -0.016 \\
\hline \multirow[t]{2}{*}{$b^{\prime}$} & 0.443 & 0.468 & 0.489 & 0.497 & 0.459 & 0.467 & 0.486 & 0.494 \\
\hline & \multicolumn{8}{|c|}{ Hysteresis model BS } \\
\hline$\mu$ & 2 & 3 & 4 & 5 & 2 & 3 & 4 & 5 \\
\hline$a_{1}^{\prime}$ & 0.66 & 0.362 & 0.338 & 0.406 & 0.724 & 0.328 & 0.274 & 0.349 \\
\hline$b_{1}^{\prime}$ & 0.043 & 0.129 & 0.168 & 0.167 & 0.0383 & 0.135 & 0.18 & 0.175 \\
\hline$T_{1}(\mathrm{~s})$ & 0.466 & 0.820 & 0.777 & 0.663 & 0.456 & 0.952 & 0.993 & 0.812 \\
\hline$C^{\prime}$ & 0.350 & 0.426 & 0.430 & 0.436 & 0.369 & 0.448 & 0.452 & 0.458 \\
\hline$T_{2}(\mathrm{~s})$ & 2.112 & 2.03 & 2.589 & 2.211 & 2.141 & 1.956 & 2.729 & 2.207 \\
\hline$a_{2}^{\prime}$ & -0.0195 & -0.0214 & -0.0249 & -0.028 & -0.0205 & -0.0186 & -0.0212 & -0.0236 \\
\hline$b_{2}^{\prime}$ & 0.392 & 0.469 & 0.495 & 0.498 & 0.412 & 0.484 & 0.509 & 0.510 \\
\hline
\end{tabular}

TABLE 13: HE/IE spectral shape parameters for site class C.

\begin{tabular}{|c|c|c|c|c|c|c|c|c|}
\hline & \multicolumn{4}{|c|}{ Mean $+\sigma$} & \multicolumn{4}{|c|}{ Mean $+2 \sigma$} \\
\hline & \multicolumn{8}{|c|}{ Hysteresis model BP } \\
\hline$\mu$ & 2 & 3 & 4 & 5 & 2 & 3 & 4 & 5 \\
\hline$C^{\prime}$ & 0.476 & 0.592 & 0.651 & 0.676 & 0.509 & 0.605 & 0.658 & 0.684 \\
\hline$T_{2}(\mathrm{~s})$ & 5 & 3.548 & 2.674 & 2.605 & 5 & 3.727 & 2.858 & 2.742 \\
\hline$a_{1}^{\prime}$ & N/A & -0.0244 & -0.0247 & -0.0308 & N/A & -0.0123 & -0.0153 & -0.0208 \\
\hline \multirow[t]{2}{*}{$\underline{b_{1}^{\prime}}$} & N/A & 0.679 & 0.717 & 0.756 & N/A & 0.651 & 0.702 & 0.741 \\
\hline & \multicolumn{8}{|c|}{ Hysteresis model SD } \\
\hline$\mu$ & 2 & 3 & 4 & 5 & 2 & 3 & 4 & 5 \\
\hline$C^{\prime}$ & 0.6 & 0.667 & 0.699 & 0.711 & 0.607 & 0.667 & 0.697 & 0.718 \\
\hline$T_{2}(\mathrm{~s})$ & 5 & 5 & 2.441 & 1.848 & 5 & 5 & 3.244 & 2.11 \\
\hline$a_{1}^{\prime}$ & N/A & N/A & -0.0363 & -0.0388 & N/A & N/A & -0.0275 & -0.0275 \\
\hline \multirow[t]{2}{*}{$b_{1}^{\prime}$} & N/A & N/A & 0.787 & 0.783 & N/A & N/A & 0.787 & 0.776 \\
\hline & \multicolumn{8}{|c|}{ Hysteresis model BF } \\
\hline$\mu$ & 2 & 3 & 4 & 5 & 2 & 3 & 4 & 5 \\
\hline$C^{\prime}$ & 0.337 & 0.406 & 0.434 & 0.444 & 0.35 & 0.428 & 0.442 & 0.45 \\
\hline$T_{2}(\mathrm{~s})$ & 5 & 5 & 5 & 5 & 5 & 5 & 5 & 5 \\
\hline$a_{1}^{\prime}$ & N/A & N/A & N/A & N/A & N/A & N/A & N/A & N/A \\
\hline \multirow[t]{2}{*}{$b_{1}^{\prime}$} & N/A & N/A & N/A & N/A & N/A & N/A & N/A & N/A \\
\hline & \multicolumn{8}{|c|}{ Hysteresis model BS } \\
\hline$\mu$ & 2 & 3 & 4 & 5 & 2 & 3 & 4 & 5 \\
\hline$a_{1}^{\prime}$ & 0.351 & 0.39 & 0.458 & 0.424 & 0.355 & 0.395 & 0.466 & 0.436 \\
\hline$b_{1}^{\prime}$ & 0.0556 & 0.0892 & 0.102 & 0.119 & 0.0529 & 0.0871 & 0.098 & 0.113 \\
\hline$T_{1}(\mathrm{~s})$ & 0.732 & 0.745 & 0.642 & 0.644 & 0.772 & 0.806 & 0.681 & 0.707 \\
\hline$C^{\prime}$ & 0.312 & 0.38 & 0.396 & 0.392 & 0.327 & 0.406 & 0.416 & 0.421 \\
\hline$T_{2}(\mathrm{~s})$ & 5 & 5 & 5 & 5 & 5 & 5 & 5 & 5 \\
\hline$a_{2}^{\prime}$ & N/A & N/A & N/A & N/A & N/A & N/A & N/A & N/A \\
\hline$b_{2}^{\prime}$ & N/A & N/A & N/A & N/A & N/A & N/A & N/A & N/A \\
\hline
\end{tabular}


TABLE 14: HE/IE spectral shape parameters for site class D.

\begin{tabular}{|c|c|c|c|c|c|c|c|c|}
\hline \multirow[b]{3}{*}{$\mu$} & \multicolumn{4}{|c|}{ Mean $+\sigma$} & \multicolumn{4}{|c|}{ Mean $+2 \sigma$} \\
\hline & \multicolumn{8}{|c|}{ Hysteresis model BP } \\
\hline & 2 & 3 & 4 & 5 & 2 & 3 & 4 & 5 \\
\hline$C^{\prime}$ & 0.512 & 0.623 & 0.668 & 0.696 & 0.531 & 0.637 & 0.677 & 0.703 \\
\hline$T_{2}(\mathrm{~s})$ & 5 & 5 & 3.48 & 3.094 & 5 & 5 & 3.6 & 3.061 \\
\hline$a_{1}^{\prime}$ & N/A & N/A & -0.0256 & -0.0289 & N/A & N/A & -0.0244 & -0.0233 \\
\hline \multirow[t]{2}{*}{$b_{1}^{\prime}$} & N/A & N/A & 0.757 & 0.785 & N/A & N/A & 0.765 & 0.775 \\
\hline & \multicolumn{8}{|c|}{ Hysteresis model SD } \\
\hline$\mu$ & 2 & 3 & 4 & 5 & 2 & 3 & 4 & 5 \\
\hline$C^{\prime}$ & 0.609 & 0.682 & 0.699 & 0.712 & 0.617 & 0.686 & 0.700 & 0.712 \\
\hline$T_{2}(\mathrm{~s})$ & 2.230 & 2.071 & 1.486 & 1.321 & 2.368 & 2.162 & 1.633 & 1.605 \\
\hline$a_{1}^{\prime}$ & -0.0142 & -0.0262 & -0.0283 & -0.0335 & -0.0142 & -0.0262 & -0.0235 & -0.0291 \\
\hline \multirow[t]{2}{*}{$b_{1}^{\prime}$} & 0.641 & 0.736 & 0.741 & 0.756 & 0.642 & 0.732 & 0.738 & 0.759 \\
\hline & \multicolumn{8}{|c|}{ Hysteresis model BF } \\
\hline$\mu$ & 2 & 3 & 4 & 5 & 2 & 3 & 4 & 5 \\
\hline$C^{\prime}$ & 0.336 & 0.417 & 0.442 & 0.460 & 0.349 & 0.426 & 0.45 & 0.469 \\
\hline$T_{2}(\mathrm{~s})$ & 5 & 5 & 5 & 2.99 & 5 & 5 & 5 & 3.066 \\
\hline$a_{1}^{\prime}$ & N/A & N/A & N/A & -0.038 & N/A & N/A & N/A & -0.0383 \\
\hline \multirow[t]{2}{*}{$b_{1}^{\prime}$} & N/A & N/A & N/A & 0.574 & N/A & N/A & N/A & 0.587 \\
\hline & \multicolumn{8}{|c|}{ Hysteresis model BS } \\
\hline$\mu$ & 2 & 3 & 4 & 5 & 2 & 3 & 4 & 5 \\
\hline$a_{1}^{\prime}$ & 0.367 & 0.437 & 0.408 & 0.395 & 0.373 & 0.473 & 0.448 & 0.427 \\
\hline$b_{1}^{\prime}$ & 0.0493 & 0.0813 & 0.111 & 0.127 & 0.0477 & 0.0752 & 0.105 & 0.121 \\
\hline$T_{1}(\mathrm{~s})$ & 0.755 & 0.678 & 0.696 & 0.680 & 0.773 & 0.659 & 0.671 & 0.682 \\
\hline$C^{\prime}$ & 0.326 & 0.377 & 0.395 & 0.395 & 0.336 & 0.387 & 0.405 & 0.412 \\
\hline$T_{2}(\mathrm{~s})$ & 5 & 5 & 5 & 5 & 5 & 5 & 5 & 5 \\
\hline$a_{2}^{\prime}$ & N/A & N/A & N/A & N/A & N/A & N/A & N/A & N/A \\
\hline$b_{2}^{\prime}$ & N/A & N/A & N/A & N/A & N/A & N/A & N/A & N/A \\
\hline
\end{tabular}

TABLE 15: HE/IE spectra shape parameters for site class E.

\begin{tabular}{|c|c|c|c|c|c|c|c|c|}
\hline \multirow[b]{3}{*}{$\mu$} & \multicolumn{4}{|c|}{ Mean $+\sigma$} & \multicolumn{4}{|c|}{ Mean $+2 \sigma$} \\
\hline & \multicolumn{8}{|c|}{ Hysteresis model BP } \\
\hline & 2 & 3 & 4 & 5 & 2 & 3 & 4 & 5 \\
\hline$C^{\prime}$ & 0.521 & 0.651 & 0.693 & 0.717 & 0.535 & 0.658 & 0.7 & 0.724 \\
\hline$T_{2}(\mathrm{~s})$ & 3.808 & 3.45 & 3.241 & 2.905 & 3.857 & 3.547 & 3.316 & 2.852 \\
\hline$a_{1}^{\prime}$ & -0.0567 & -0.07 & -0.0575 & -0.0483 & -0.0571 & -0.0771 & -0.06 & -0.0457 \\
\hline \multirow[t]{2}{*}{$b_{1}^{\prime}$} & 0.736 & 0.892 & 0.88 & 0.858 & 0.756 & 0.932 & 0.899 & 0.855 \\
\hline & \multicolumn{8}{|c|}{ Hysteresis model SD } \\
\hline$\mu$ & 2 & 3 & 4 & 5 & 2 & 3 & 4 & 5 \\
\hline$C^{\prime}$ & 0.633 & 0.708 & 0.736 & 0.746 & 0.631 & 0.704 & 0.73 & 0.741 \\
\hline$T_{2}(\mathrm{~s})$ & 2.307 & 1.867 & 1.317 & 1.2 & 2.4 & 1.861 & 1.357 & 1.353 \\
\hline$a_{1}^{\prime}$ & -0.0483 & -0.0471 & -0.0459 & -0.0521 & -0.0483 & -0.0471 & -0.0395 & -0.0476 \\
\hline \multirow[t]{2}{*}{$b_{1}^{\prime}$} & 0.745 & 0.796 & 0.796 & 0.809 & 0.739 & 0.780 & 0.783 & 0.805 \\
\hline & \multicolumn{8}{|c|}{ Hysteresis model BF } \\
\hline$\mu$ & 2 & 3 & 4 & 5 & 2 & 3 & 4 & 5 \\
\hline$C^{\prime}$ & 0.347 & 0.426 & 0.454 & 0.469 & 0.355 & 0.432 & 0.462 & 0.476 \\
\hline$T_{2}(\mathrm{~s})$ & 3.053 & 2.428 & 2.323 & 2.136 & 3.07 & 2.472 & 2.279 & 2.273 \\
\hline$a_{1}^{\prime}$ & -0.021 & -0.0225 & -0.03 & -0.035 & -0.021 & -0.0225 & -0.0275 & -0.035 \\
\hline \multirow[t]{2}{*}{$b_{1}^{\prime}$} & 0.411 & 0.481 & 0.524 & 0.544 & 0.419 & 0.481 & 0.525 & 0.555 \\
\hline & \multicolumn{8}{|c|}{ Hysteresis model BS } \\
\hline$\mu$ & 2 & 3 & 4 & 5 & 2 & 3 & 4 & 5 \\
\hline$a_{1}^{\prime}$ & 0.332 & 0.313 & 0.256 & 0.208 & 0.358 & 0.306 & 0.241 & 0.195 \\
\hline$b_{1}^{\prime}$ & 0.0591 & 0.0968 & 0.122 & 0.143 & 0.054 & 0.0945 & 0.118 & 0.139 \\
\hline$T_{1}(\mathrm{~s})$ & 0.767 & 0.824 & 0.956 & 1.095 & 0.748 & 0.867 & 1.096 & 1.334 \\
\hline$C^{\prime}$ & 0.314 & 0.355 & 0.367 & 0.372 & 0.322 & 0.359 & 0.382 & 0.3991 \\
\hline$T_{2}(\mathrm{~s})$ & 5 & 5 & 5 & 5 & 5 & 5 & 5 & 5 \\
\hline$a_{2}^{\prime}$ & N/A & N/A & N/A & N/A & N/A & N/A & N/A & N/A \\
\hline$b_{2}^{\prime}$ & N/A & N/A & N/A & N/A & N/A & N/A & N/A & N/A \\
\hline
\end{tabular}



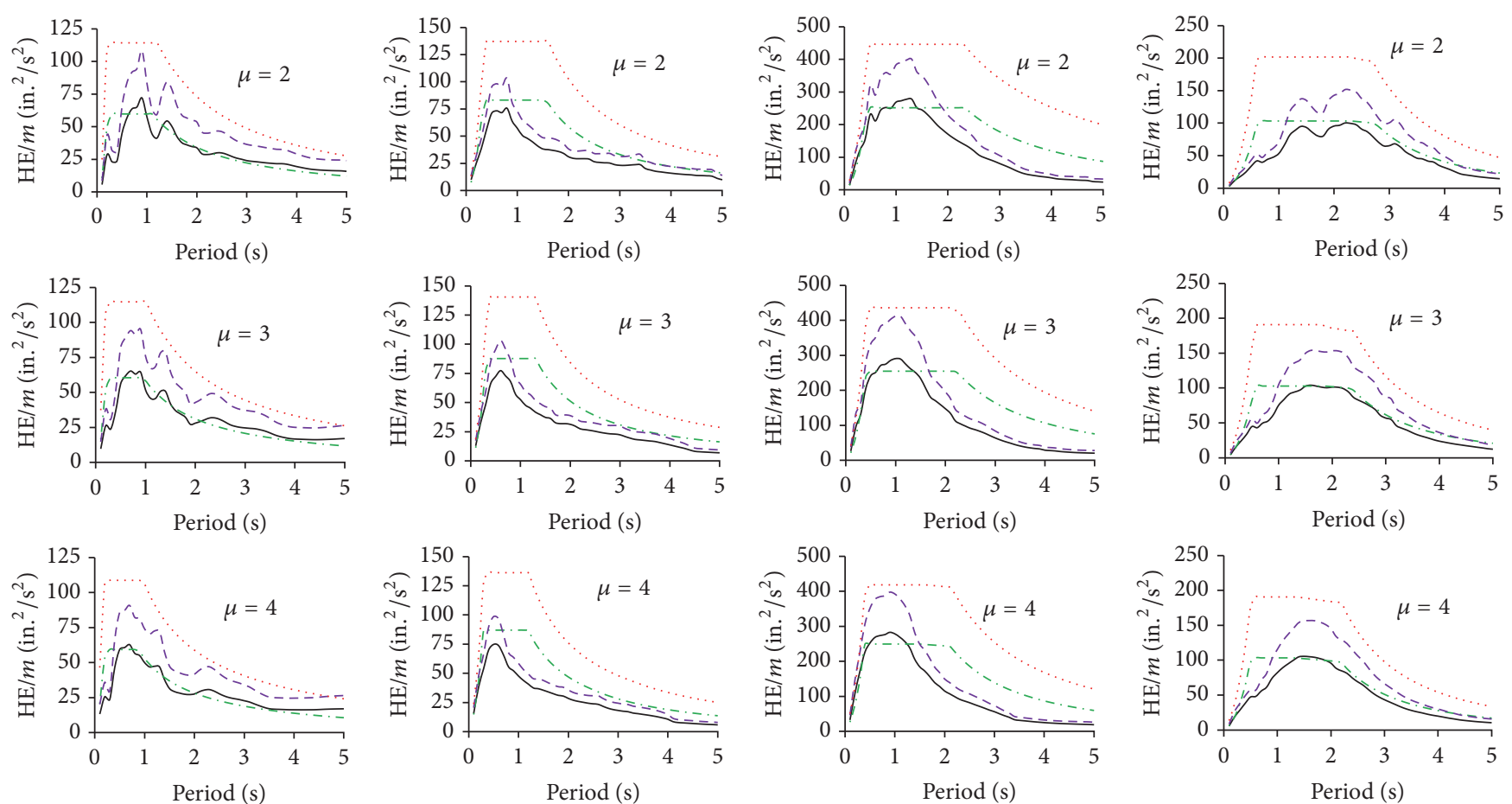

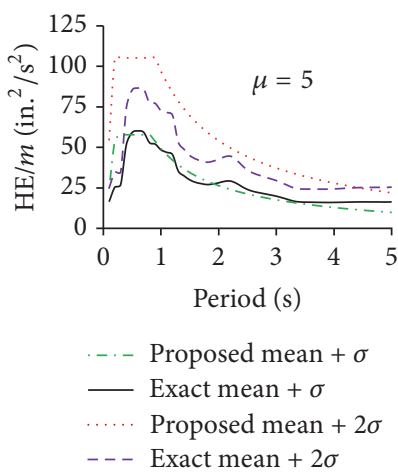

(a) Soil Site B

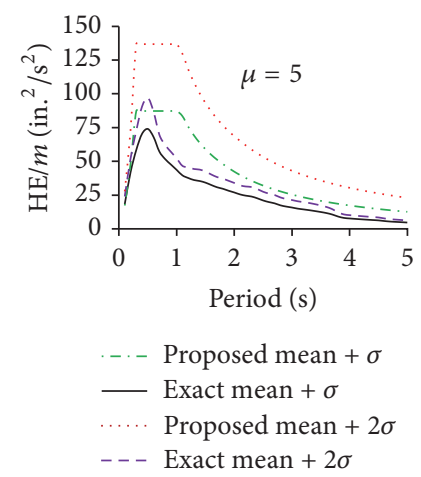

(b) Soil site C

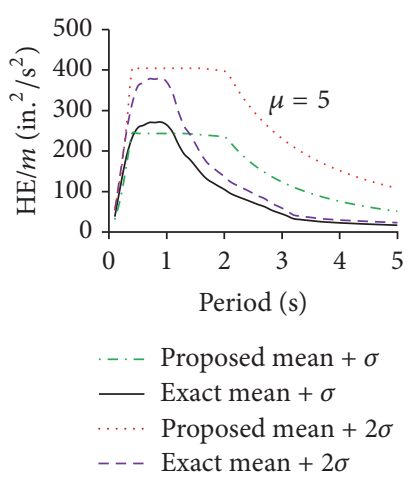

(c) Soil Site D

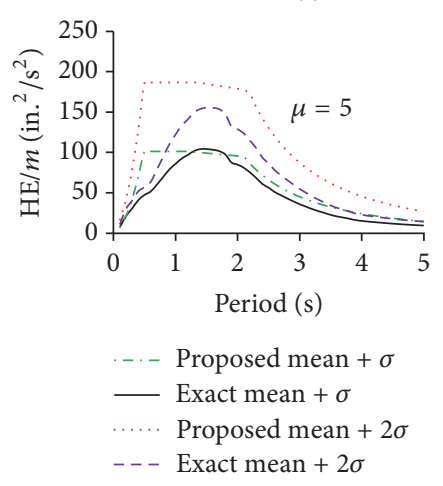

(d) Soil Site E

FIGURE 14: Comparative study of proposed hysteretic energy spectra: hysteresis model SD.

\section{Comparative Study of the Proposed Hysteretic Energy Spectra}

Scaled earthquake records shown in Tables 10 and 11 are now used to examine the validity of the proposed HE/IE spectra. Hysteretic spectra computed using the approach outlined above are compared with hysteretic spectra obtained from nonlinear time history analysis of the ground motions given in Table 10 using each of the four hysteresis models. The comparisons for the mean $+\sigma$ and mean $+2 \sigma$ hysteretic energy spectra are shown in Figures 13-16. From these figures, it can be seen that the proposed hysteretic energy spectra give reasonably good to conservative results for a large range of periods for all four hysteresis models used in the study.

\section{Summary and Conclusions}

In an energy-based seismic design, the basic premise is that a structure needs to be designed so it possesses sufficient energy absorbing capacity to surmount the input energy (IE) generated from ground motions. This paper addresses the energy demand aspect of this design methodology by developing normalized input energy spectra for four soil site classes using four hysteresis models at different levels of ductility. These constant ductility normalized input energy spectra were developed for SDOF systems subjected to four ensembles of ground motion records representing the four soil site classes. The normalizing was performed to reduce data scattering and to allow for nondimensionalization. The normalization parameter is referred to as the velocity index (VI), obtained as the product of the peak ground velocity (PGV) and cumulative absolute velocity (CAV) of each earthquake. Ductility dependent equations representing the mean $+\sigma$ and mean $+2 \sigma$ normalized input energy (NE) spectra are then presented and compared with the input energy spectra generated for the fault normal and fault parallel components of three commonly studied earthquakes. Hysteretic or damage energy (HE) spectra are then developed, and 

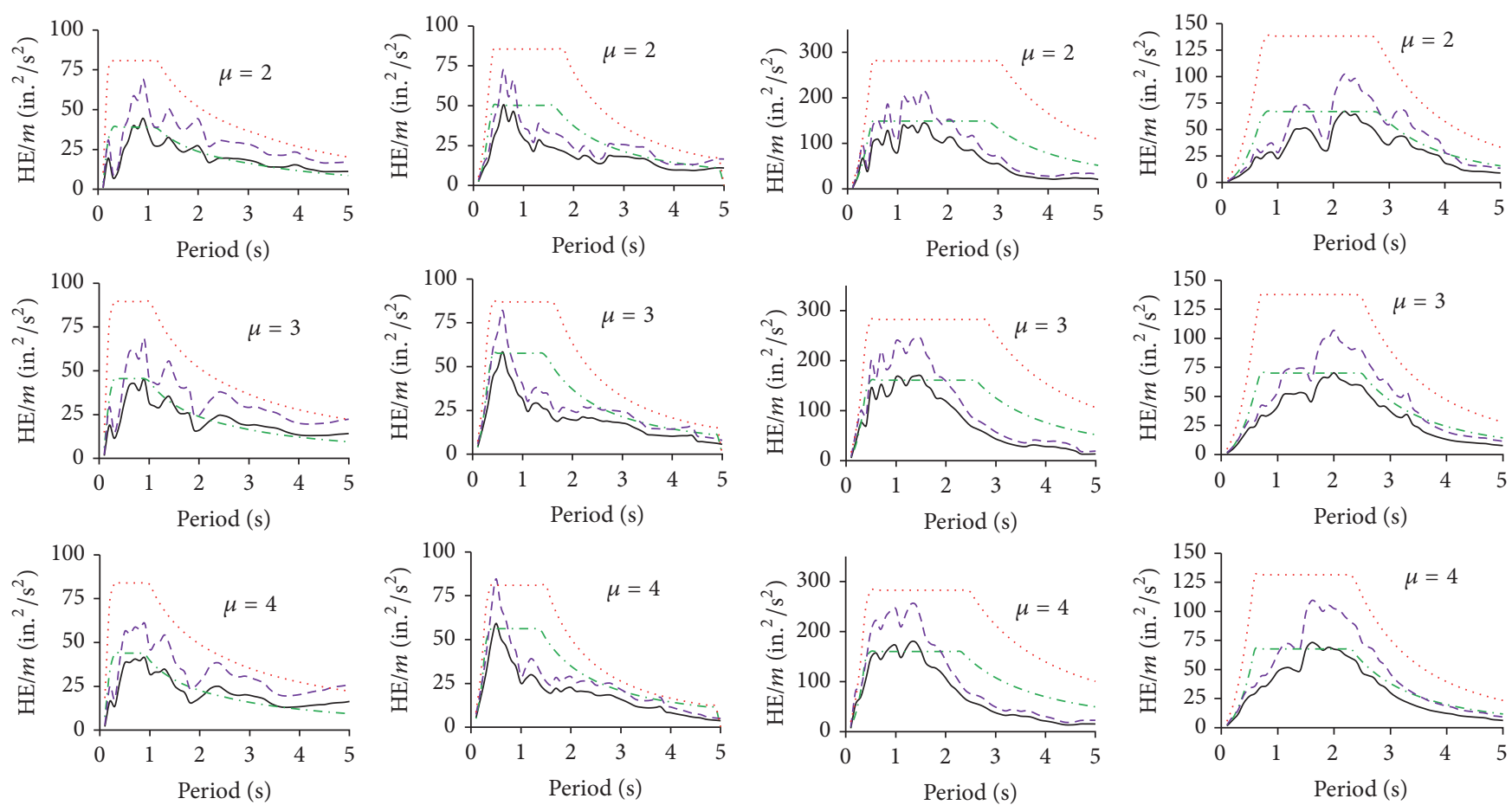

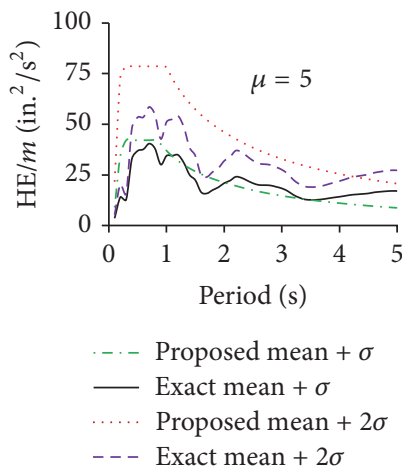

(a) Soil site $B$

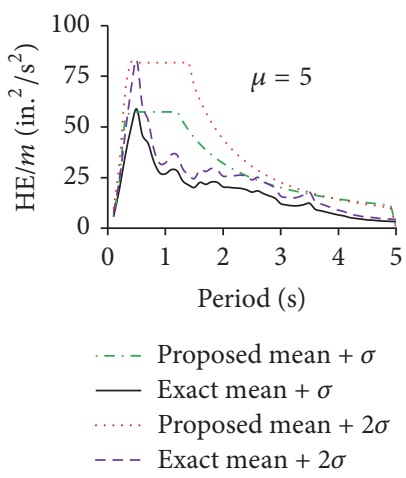

(b) Soil site C
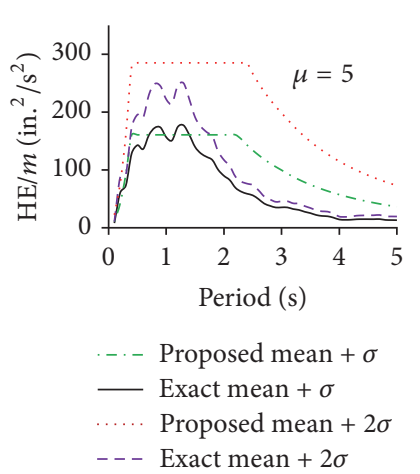

(c) Soil site D

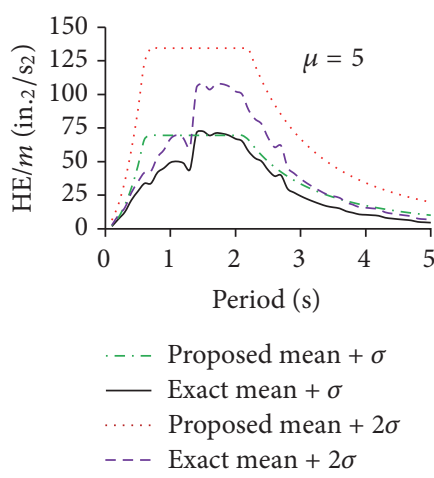

(d) Soil site E

FIGURE 15: Comparative study of proposed hysteretic energy spectra: hysteresis model BF.

equations for the mean $+\sigma$ and mean $+2 \sigma \mathrm{HE} / \mathrm{IE}$ spectra for four ductility levels and soil site classes are presented and compared with the hysteretic energy spectra generated for the same three earthquakes. The comparisons show that the proposed input energy and hysteretic energy spectra generally give reasonably good to mostly conservative results over the period range used in the study.

\section{Nomenclature}
a: Curve-fitting constant
$b$ : Curve-fitting constant
$c$ : Damping coefficient
$f_{s}$ : Restoring force
$\mathrm{ft}:$ Feet $(1 \mathrm{ft}=30.5 \mathrm{~cm})$
g: Acceleration due to gravity
$k$ : Curve-fitting constant
$m$ : Mass
$n$ : Curve-fitting constant
s: $\quad$ Second
$t$ : Duration of ground motion
$u$ : $\quad$ Relative displacement
$\dot{u}$ : Relative velocity
$\ddot{u}: \quad$ Relative acceleration
$\ddot{u}_{g}$ : Ground acceleration
BF: Bilinear flag hysteresis model
BP: Bilinear plastic hysteresis model
BS: Bilinear slip hysteresis model
C: $\quad$ Curve-fitting constant
CAV: Cumulative absolute velocity
DBD: Displacement-based design
$E_{a}$ : Absorbed energy
$E_{d}$ : Damping energy
$E_{\mathrm{kr}}: \quad$ Relative kinetic energy
EBSD: Energy-based seismic design
FBD: Force-based design 

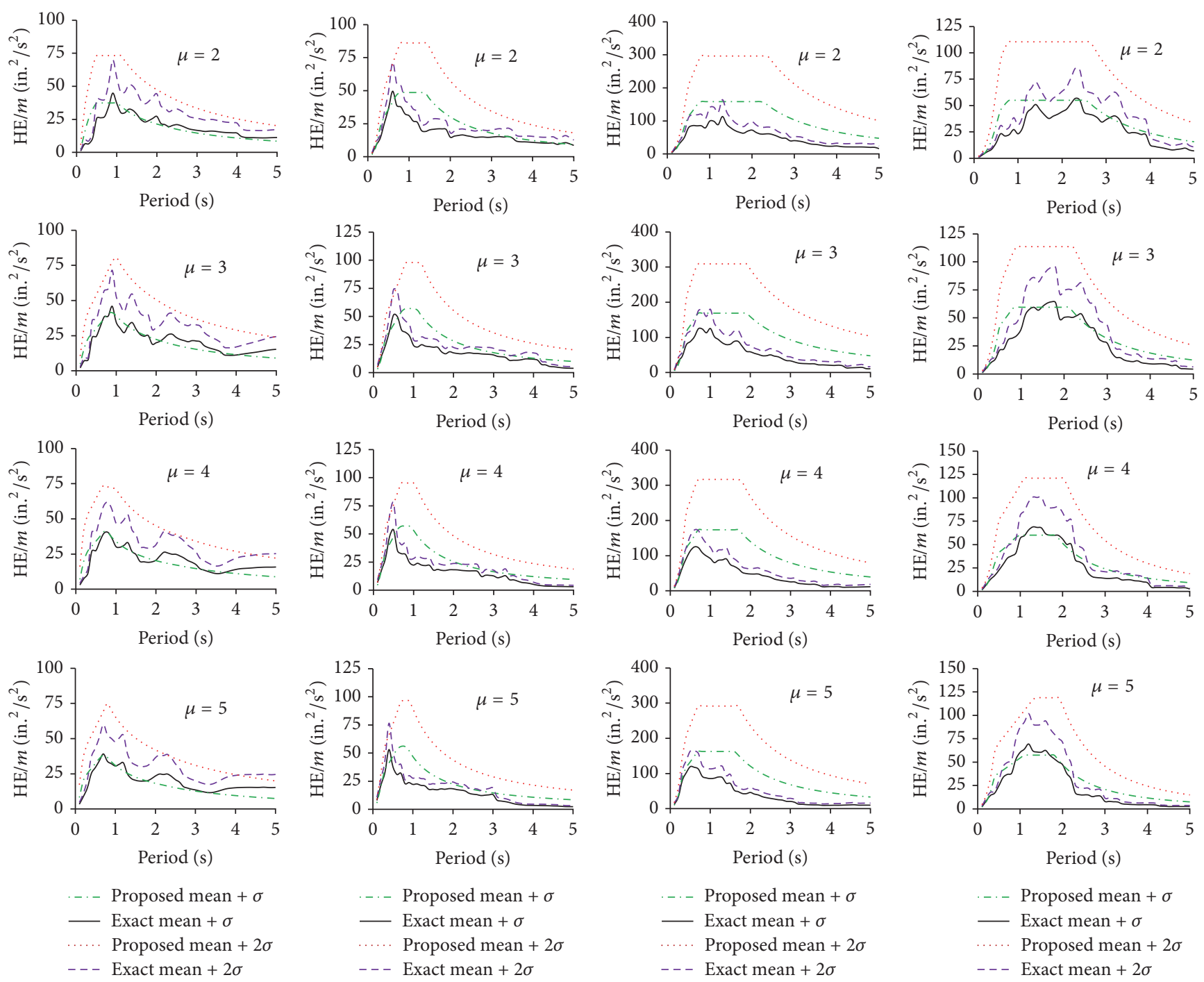

(a) Soil site B

(b) Soil site $\mathrm{C}$

(c) Soil site D

(d) Soil site $\mathrm{E}$

FIGURE 16: Comparative study of proposed hysteretic energy spectra: hysteresis model BS.

HE: Hysteretic energy

$I_{A}: \quad$ Arias intensity

$I_{d}: \quad$ Seismic damage index

IE: $\quad$ Relative input energy

MDOF: Multi-degree-of-freedom system

$M_{w}$ : Moment magnitude

NE: Normalized energy

NGA: Next-generation attenuation

PGA: Peak ground acceleration

PGV: Peak ground velocity

$R_{\text {rup }}$ : Closest distance to rupture plane

$S_{a}: \quad$ Spectral acceleration

SD: $\quad$ Modified clough stiffness degradation hysteresis model

SDOF: Single degree of freedom system

$T_{1}, T_{2}$ : Demarcating periods

VI: $\quad$ Velocity index
$V_{s 30}$ : Average shear wave velocity of the upper $30 \mathrm{~m}$ depth of soil profile

$\mu$ : Ductility

$\sigma: \quad$ Standard deviation.

\section{Competing Interests}

The authors declare that there is no conflict of interests regarding the publication of this paper.

\section{References}

[1] R. S. H. Smith and W. K. Tso, "Inconsistency of force-based design procedure," Journal of Seismology and Earthquake Engineering, vol. 4, no. 1, pp. 46-54, 2002.

[2] M. J. N. Priestley, G. M. Calvi, and M. J. Kowalsky, DisplacementBased Seismic Design of Structures, IUSS Press, Pavia, Italy, 2007. 
[3] FEMA 440, Improvement of Nonlinear Static Seismic Analysis Procedures, Federal Emergency Management Agency, Washington, DC, USA, 2005.

[4] E. Hernandez-Montes, O.-S. Kwon, and M. A. Aschheim, "An energy-based foftimulatzon for firstand Multiplemode nonlinear static (pushover) analyses," Journal of Earthquake Engineering, vol. 8, no. 1, pp. 69-88, 2004.

[5] G. Manoukas, A. Athanatopoulou, and I. Avramidis, "Static pushover analysis based on an energy-equivalent SDOF system," Earthquake Spectra, vol. 27, no. 1, pp. 89-105, 2011.

[6] E. Hernández-Montes, M. A. Aschheim, and L. M. Gil-Martín, "Energy components in nonlinear dynamic response of SDOF systems," Nonlinear Dynamics, vol. 82, no. 1-2, pp. 933-945, 2015.

[7] M. Bruneau and N. Wang, "Some aspects of energy methods for the inelastic seismic response of ductile SDOF structures," Engineering Structures, vol. 18, no. 1, pp. 1-12, 1996.

[8] M. Fabrizio, S. Bruno, L. Decanini, and R. Saragoni, "Correlations between energy and displacement demands for performance-based seismic engineering," Pure and Applied Geophysics, vol. 168, no. 1-2, pp. 237-259, 2011.

[9] G. W. Housner, "Limit design of structures to resist earthquakes," in Proceedings of the 1st World Conference on Earthquake Engineering, vol. 5, pp. 1-13, Berkeley, Calif, USA, June 1956.

[10] H. Akiyama, Earthquake-Resistant Limit State Design for Buildings, University of Tokyo Press, Tokyo, Japan, 1985.

[11] H. Kuwamura and T. V. Galambos, "Earthquake load for structural reliability," Journal of Structural Engineering, vol. 115, no. 6, pp. 1446-1462, 1989.

[12] P. Fajfar, T. Vidic, and M. Fischinger, "Seismic demand in medium- and long-period structures," Earthquake Engineering \& Structural Dynamics, vol. 18, no. 8, pp. 1133-1144, 1989.

[13] M. D. Trifunac and A. G. Brady, "A study on the duration of strong earthquake ground motion," Bulletin of Seismological Society of America, vol. 65, pp. 581-626, 1975.

[14] C.-M. Uang and V. V. Bertero, "Evaluation of seismic energy in structures," Earthquake Engineering and Structural Dynamics, vol. 19, no. 1, pp. 77-90, 1990.

[15] G. Manfredi, "Evaluation of seismic energy demand," Earthquake Engineering and Structural Dynamics, vol. 30, no. 4, pp. 485-499, 2001.

[16] P. Khashaee, Energy-based seismic design and damage assessment for structures [Ph.D. thesis], Southern Methodist University, Dallas, Tex, USA, 2004.

[17] Y.-J. Park and A. H.-S. Ang, "Mechanistic seismic damage model for reinforced concrete," Journal of Structural Engineering, vol. 111, no. 4, pp. 722-739, 1985.

[18] L. D. Decanini and F. Mollaioli, "Formulation of elastic earthquake input energy spectra," Earthquake Engineering and Structural Dynamics, vol. 27, no. 12, pp. 1503-1522, 1998.

[19] A. Benavent-Climent, L. G. Pujades, and F. López-Almansa, "Design energy input spectra for moderate-seismicity regions," Earthquake Engineering and Structural Dynamics, vol. 31, no. 5, pp. 1151-1172, 2002.

[20] A. Benavent-Climent, F. López-Almansa, and D. A. BravoGonzález, "Design energy input spectra for moderate-to-high seismicity regions based on Colombian earthquakes," Soil Dynamics and Earthquake Engineering, vol. 30, no. 11, pp. 1129$1148,2010$.

[21] G. G. Amiri, G. A. Darzi, and J. V. Amiri, "Design elastic input energy spectra based on Iranian earthquakes," Canadian Journal of Civil Engineering, vol. 35, no. 6, pp. 635-646, 2008.
[22] F. López-Almansa, A. U. Yazgan, and A. Benavent-Climent, "Design energy input spectra for high seismicity regions based on Turkish registers," Bulletin of Earthquake Engineering, vol. 11, no. 4, pp. 885-912, 2013.

[23] Y. Cheng, A. Lucchini, and F. Mollaioli, "Proposal of new ground-motion prediction equations for elastic input energy spectra," Earthquake and Structures, vol. 7, no. 4, pp. 485-510, 2014.

[24] Y. Cheng, A. Lucchini, and F. Mollaioli, "Correlation of elastic input energy equivalent velocity spectral values," Earthquake and Structures, vol. 8, no. 5, pp. 957-976, 2015.

[25] ASCE/SEI 7-10, Minimum Design Loads for Buildings and Other Structures, American Society of Civil Engineers, Reston, Va, USA, 2010.

[26] P. Fajfar and T. Vidic, "Consistent inelastic design spectra: hysteretic and input energy," Earthquake Engineering and Structural Dynamics, vol. 23, no. 5, pp. 523-537, 1994.

[27] J. F. Hall, T. H. Heaton, M. W. Halling, and D. J. Wald, "Near-source ground motion and its effects on flexible buildings," Earthquake Spectra, vol. 11, no. 4, pp. 569-605, 1995.

[28] K. W. Campbell, "Empirical near-source attenuation relationships for horizontal and vertical components of peak ground acceleration, peak ground velocity, and pseudo-absolute acceleration response spectra," Seismological Research Letters, vol. 68, no. 1, pp. 154-179, 1997.

[29] P. Bazzurro and N. Luco, "Damage potential of near-source ground motion records," in Proceedings of the 8th US National Conference on Earthquake Engineering, pp. 5061-5070, San Francisco, Calif, USA, April 2006.

[30] N. Abrahamson and W. Silva, "Summary of the Abrahamson \& Silva NGA ground-motion relations," Earthquake Spectra, vol. 24, no. 1, pp. 67-97, 2008.

[31] K. W. Campbell and Y. Bozorgnia, "NGA ground motion model for the geometric mean horizontal component of PGA, PGV, PGD and 5\% damped linear elastic response spectra for periods ranging from 0.01 to 10 s," Earthquake Spectra, vol. 24, no. 1, pp. 139-171, 2008.

[32] D. M. Boore and G. M. Atkinson, "Ground-motion prediction equations for the average horizontal component of PGA, PGV, and 5\%-damped PSA at spectral periods between $0.01 \mathrm{~s}$ and 10.0 s," Earthquake Spectra, vol. 24, no. 1, pp. 99-138, 2008.

[33] B. S.-J. Chiou and R. R. Youngs, "An NGA model for the average horizontal component of peak ground motion and response spectra," Earthquake Spectra, vol. 24, no. 1, pp. 173-215, 2008.

[34] M. C. Kunde and R. S. Jangid, "Seismic behavior of isolated bridges-a state-of-the-art review," Electronic Journal of Structural Engineering, vol. 3, pp. 140-170, 2003.

[35] IBC, International Building Code, International Code Council, Country Clubs Hill, Ill, USA, 2015.

[36] AASHTO, Guide Specifications for LRFD Seismic Bridge Design, American Association of State Highway and Transportation Officials, Washington, DC, USA, 2009.

[37] B.-F. Peng and J. P. Conte, "Statistical insight into constantductility design using a non-stationary earthquake ground motion model," Earthquake Engineering and Structural Dynamics, vol. 26, no. 9, pp. 895-916, 1997.

[38] M. Inel, M. A. Aschheim, and D. P. Abrams, "An algorithm for computing isoductile response spectra," Journal of Earthquake Engineering, vol. 6, no. 3, pp. 375-390, 2002.

[39] C. Zhai and L. Xie, "Constant-ductility strength demand spectra for seismic design of structures," Earthquake Engineering 
and Engineering Vibration, vol. 4, no. 2, Article ID 16713664(2005)02-0243-08, pp. 243-250, 2005.

[40] A. K. Chopra and R. K. Goel, "Capacity-demand-diagram methods based on inelastic design spectrum," Earthquake Spectra, vol. 15, no. 4, pp. 637-655, 1999.

[41] S. A. Mahin and V. V. Bertero, "Nonlinear seismic response of a coupled wall system," Journal of the Structural Division, vol. 102, no. 9, pp. 1759-1780, 1976.

[42] J. M. Ricles, R. Sause, M. M. Garlock, and C. Zhao, "Posttensioned seismic-resistant connections for steel frames," Journal of Structural Engineering, vol. 127, no. 2, pp. 113-121, 2001.

[43] C. Christopoulos, A. Filiatrault, and B. Folz, "Seismic response of self-centering hysteretic SDOF systems," Earthquake Engineering and Structural Dynamics, vol. 31, no. 5, pp. 1131-1150, 2002.

[44] F. C. Filippou, E. P. Popov, and V. V. Bertero, "Modeling of R/C joints under cyclic excitations," Journal of Structural Engineering, vol. 109, no. 11, pp. 2666-2684, 1983.

[45] M. Nakashima, K. Saburi, and B. Tsuji, "Energy input and dissipation behaviour of structures with hysteretic dampers," Earthquake Engineering and Structural Dynamics, vol. 25, no. 5, pp. 483-496, 1996.

[46] EPRC, "A criterion for determining exceedance of the operating basis earthquake," EPRC Report 2848-16, Electric Power Research Corporation, 1998.

[47] A. Arias, A Measure of the Earthquake Intensity in Seismic Design for Nuclear Power Plants, MIT Press, Cambridge, Mass, USA, 1970.

[48] M. Power, B. Chiou, N. Abrahamson, Y. Bozorgnia, T. Shantz, and C. Roblee, "An overview of the NGA project," Earthquake Spectra, vol. 24, no. 1, pp. 3-21, 2008.

[49] K. W. Campbell and Y. Bozorgnia, "A ground motion prediction equation for the horizontal component of cumulative absolute velocity (CAV) based on the PEER-NGA strong motion database," Earthquake Spectra, vol. 26, no. 3, pp. 635-650, 2010.

[50] B. A. Bradley, "Empirical correlations between cumulative absolute velocity and amplitude-based ground motion intensity measures," Earthquake Spectra, vol. 28, no. 1, pp. 37-54, 2012.

[51] BISPEC, “Earthquake Solutions," 2012, http://www.eqsols.com.

[52] FEMA P695, Recommended Methodology for Quantification of Building System Performance and Response Parameters, Federal Emergency Management Agency, Washington, DC, USA, 2009.

[53] PEER, "Pacific Earthquake Engineering Research Center Beta version Data Base," http://peer.berkeley.edu/peer_ground_ motion_database.

[54] L. Ye, G. Cheng, and X. Qu, "Study on energy based seismic design method and the application for steel braced frame structures," in Proceedings of the 6th International Conference on Urban Earthquake Engineering, pp. 417-428, Tokyo Institute of Technology, Tokyo, Japan, 2009.

[55] F. Mollaioli, S. Bruno, L. D. Decanini, and G. F. Panza, "Characterization of the dynamic response of structures to damaging pulse-type near-fault ground motions," Meccanica, vol. 41, no. 1, pp. 23-46, 2006. 


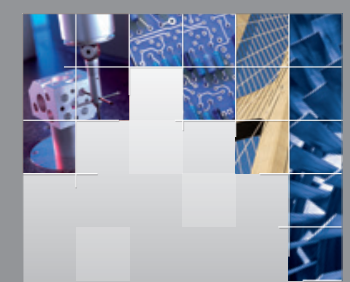

\section{Enfincering}
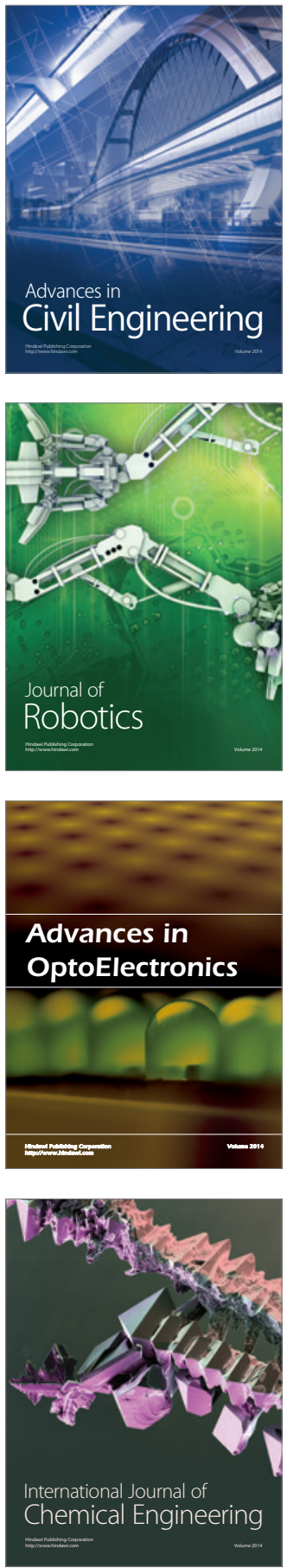

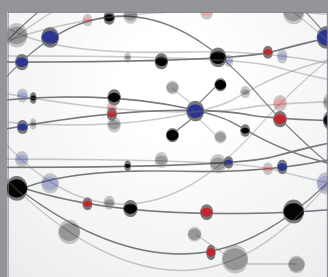

The Scientific World Journal

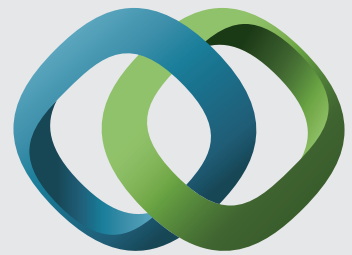

\section{Hindawi}

Submit your manuscripts at

http://www.hindawi.com
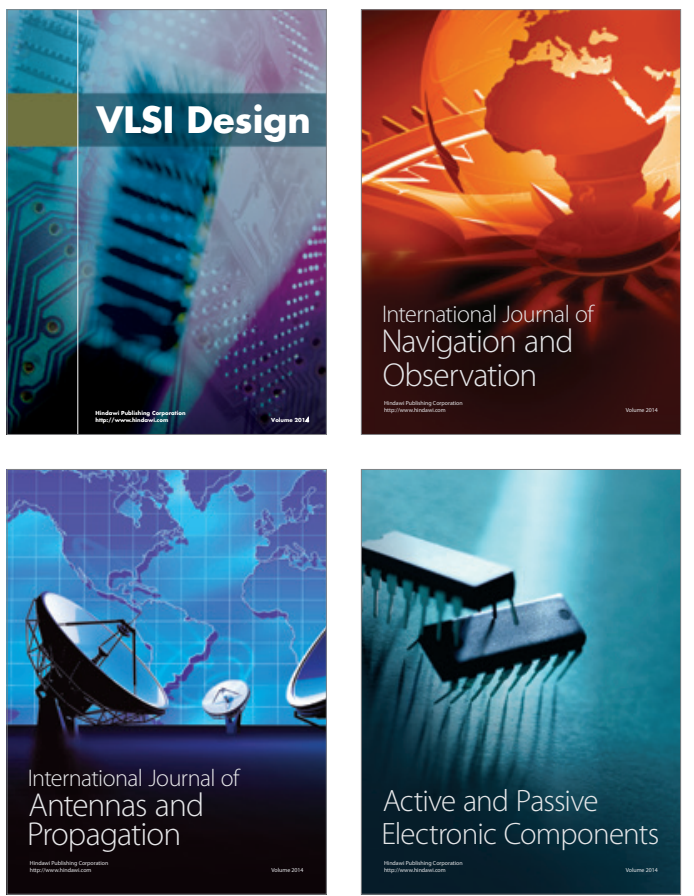
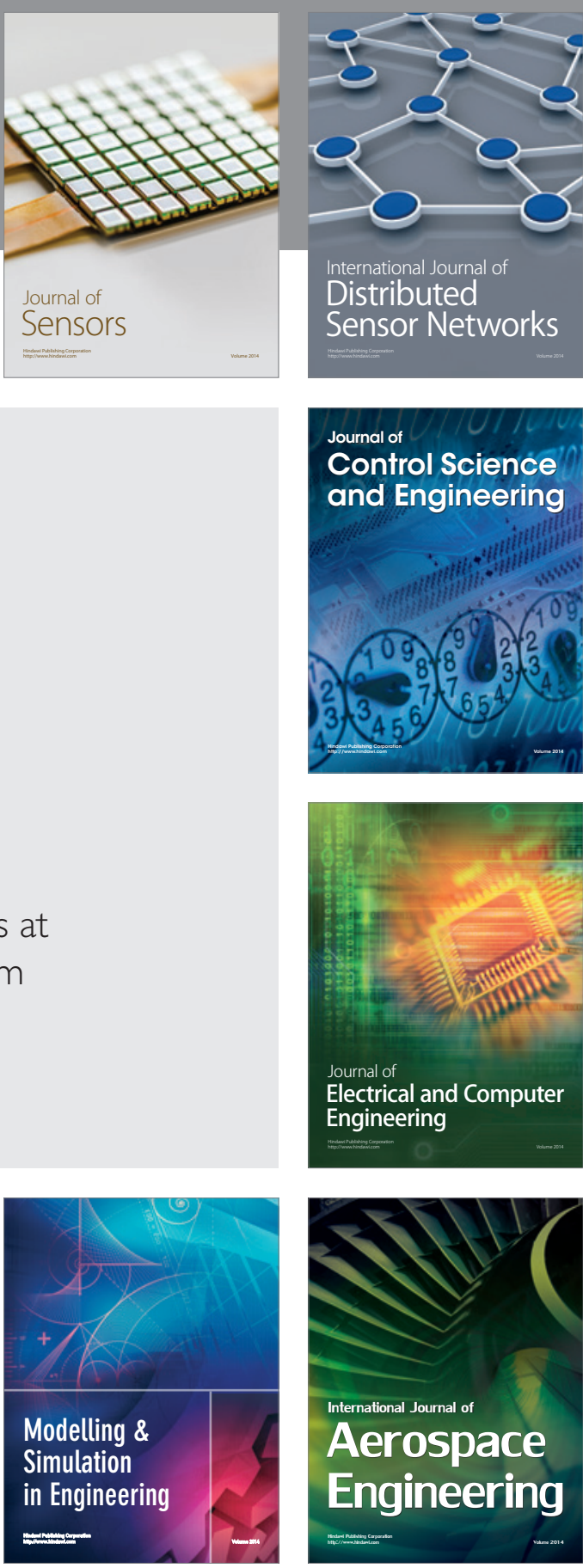

International Journal of

Distributed

Sensor Networks

Journal of

Control Science

and Engineering
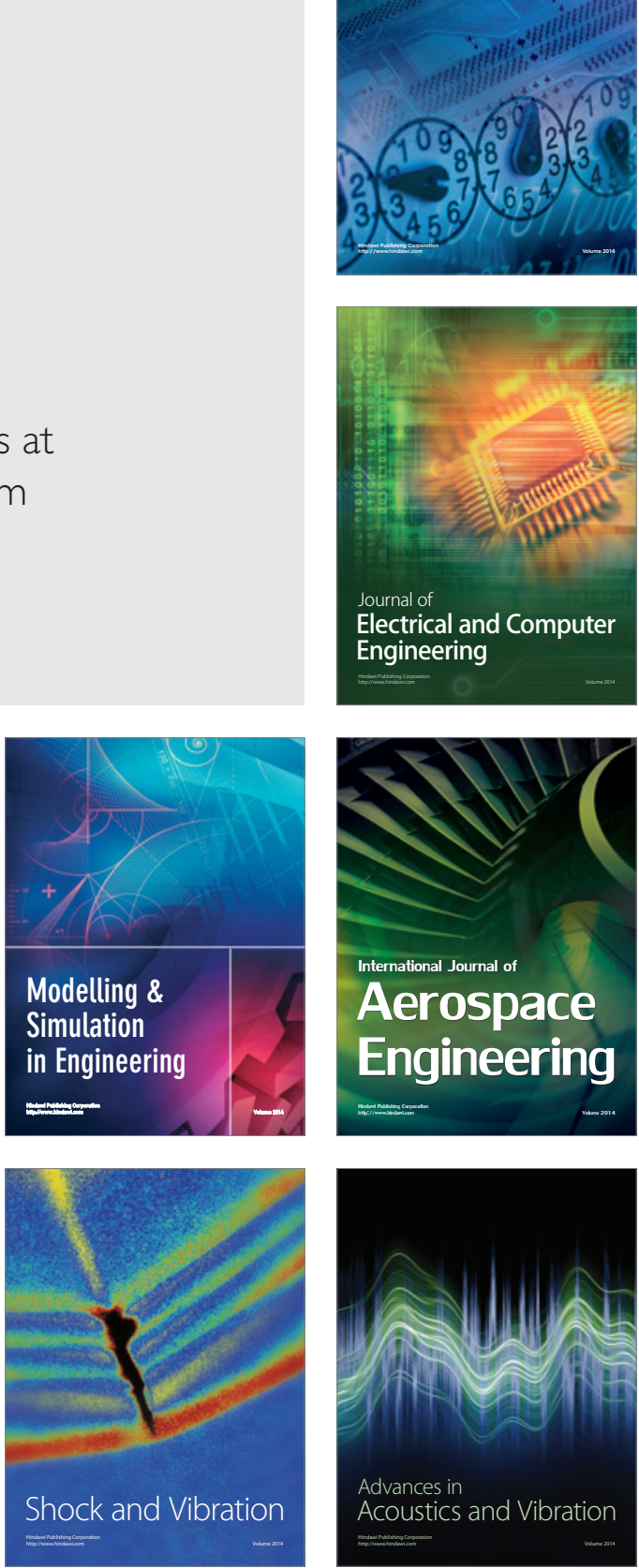